\title{
EFFECT OF LOAD ON CLOSE-COUPLED POST-INJECTION EFFICACY FOR SOOT REDUCTION IN AN OPTICAL, HEAVY-DUTY DIESEL RESEARCH ENGINE
}

\author{
Jacqueline O'Connor and Mark P. B. Musculus \\ Sandia National Laboratories \\ Livermore, California, USA
}

\begin{abstract}
The use of close-coupled post injections of fuel is an incylinder soot-reduction technique that has much promise for high efficiency, heavy-duty diesel engines. Close-coupled post injections, short injections of fuel that occur soon after the end of the main fuel injection, have been known to reduce engineout soot at a wide range of engine operating conditions, including variations in injection timing, EGR level, load, boost, and speed. While many studies have investigated the performance of post injections, the details of the mechanism by which soot is reduced remains unclear. In this study, we have measured the efficacy of post injections over a range of load conditions, at constant speed, boost, and rail pressure, in a heavy-duty, optically-accessible research diesel engine. Here, the base load is varied by changing the main-injection duration. Measurements of engine-out soot indicate that not only does the efficacy of a post injection decrease at higher engine loads, but that the range of post-injection durations over which soot reduction is achievable is limited at higher loads. Optical measurements, including natural luminescence of soot and planar laser-induced incandescence of soot, provide information about the spatio-temporal development of in-cylinder soot through the cycle in cases with and without post injections. The optical results indicate that the post injection behaves similarly at different loads, but that its relative efficacy decreases due to the increase in soot resulting from longer main-injection durations.
\end{abstract}

\section{NOMENCLATURE}

AEI

AHRR

ATDC

BDC

BTDC

C
CAD

CDCP

CDVP

CSOI

DI

DOI1 $_{C}$

$\mathrm{DOI}_{\mathrm{C}}$

DPF

EGR

EOI1

EOI2

ESC

EVO

FSN

gIMEP

LII

LTC

NEDC

NL

PAH

RPM

SCR

$\mathrm{SOI1}_{\mathrm{C}}$

$\mathrm{SOI} 2_{\mathrm{C}}$

TDC

UHC

UV
Crank angle degree position (360 CAD is TDC of compression Stroke)

Constant dwell, constant phasing injection schedule

Constant dwell, variable phasing injection schedule

Constant start of injection schedule

Direct injection

Commanded duration of main injection (in microseconds)

Commanded duration of post injection (in microseconds)

Diesel particulate filter

Exhaust gas recirculation

End of main injection

End of post injection

European steady-state cycle

Exhaust valve open

Filter smoke number

Gross indicated mean effective pressure

Laser induced incandescence

Low temperature combustion

New European Drive Cycle

Natural luminescence

Poly-cyclic aromatic hydrocarbon

Revolutions per minute

Selective catalytic reactor

Commanded start of main injection (in crank angle degrees)

Commanded start of post injection (in crank angle degrees)

Top dead center

Unburned hydrocarbons

Ultra-violet 


\section{INTRODUCTION}

Several methods for reducing emissions of particulate matter $(\mathrm{PM})$ and nitrogen oxides $\left(\mathrm{NO}_{\mathrm{x}}\right)$ from heavy-duty diesel engines have been proposed to meet emissions regulations in the United States [1, 2], Europe [3], and Asia [4]. These include aftertreatment and in-cylinder techniques, both of which have already been implemented in commercial hardware. Aftertreatment systems have proved to be an effective way to reduce $\mathrm{PM}$ emissions, but packaging and cost constraints, as well as fuel penalties associated with aftertreatment management, motivate improvement of in-cylinder techniques to reduce the burden on aftertreatment.

Several in-cylinder strategies have been proposed for meeting $\mathrm{PM}$ and $\mathrm{NO}_{\mathrm{x}}$ emissions targets without exhaust aftertreatment, but they typically increase other emissions and they sometimes reduce fuel efficiency, including decreases in both combustion efficiency and thermal efficiency. For example, low-temperature combustion (LTC) operation using high levels of exhaust gas recirculation (EGR) has been shown to significantly reduce $\mathrm{PM}$ and $\mathrm{NO}_{\mathrm{x}}$ emissions [5-8]. LTC decreases combustion temperatures while increasing precombustion fuel/air mixing through a combination of dilution and non-conventional fuel injection timings. This method of operation, however, can lead to large increases in unburned hydrocarbon (UHC) and carbon monoxide (CO) emissions [9$11]$.

Current production diesel engines typically use more moderate levels of EGR with more conventional fuel injection timings to lessen, but not eliminate, the burden on the exhaust aftertreatment systems. These strategies reduce $\mathrm{NO}_{\mathrm{x}}$ somewhat, and with higher combustion temperatures and less precombustion mixing than more aggressive LTC strategies, they do not suffer from excessive UHC and $\mathrm{CO}$ emissions. While moderate EGR helps to reduce $\mathrm{NO}_{\mathrm{x}}$ with conventional diesel fuel injection timings, it typically increases net soot formation, so that engine-out PM may increase.

Post injections of fuel have been used at conventional fuel injection timings with some success to reduce engine-out soot, a major component of PM [12-17]. Post injections are small fuel injections (typically up to approximately $20 \%$ of total fuel) that occur after the main fuel injection. Post injections can be introduced shortly after the main injection, such that they fully ignite and combust, or they can be introduced late in the cycle, where they typically burn only partially, if at all. Late-cycle post injections are typically for aftertreatment management, and are not considered here.

Numerous studies have reported the efficacy of post injections for in-cylinder soot reduction at a variety of postinjection timings. Post-injections for in-cylinder soot reduction can be either close-coupled if they are introduced shortly after the main injection (within a few crank angle degrees), or nonclose coupled, if they are introduced much later after the main injection (but not so late that their combustion is far from complete). Both close-coupled [15, 17-19] and non-close- coupled $[13,20,21]$ post injections have been shown to significantly reduce engine-out soot.

One of the advantages of using close-coupled post injections for soot reduction is that the phasing of combustion for the post-injection is favorable for fuel efficiency while soot is simultaneously reduced. Studies by several authors [19, 2125] have shown that penalties in efficiency can largely be avoided by using close-coupled timings.

Throughout the post-injection literature, studies have generally offered three explanations for how post injections reduce soot. The most prevalent explanation is that the postinjection jet enhances mixing of the main-injection mixture with fresh oxygen $[13,15,17,20,23,26-29]$. This mixing can have two effects. First, the additional mixing can increase soot oxidation by providing more oxygen to regions where soot from the main injection was formed [13, 15-17, 26]. Additionally, enhanced mixing can reduce soot formation by providing more oxygen to the fuel-rich regions where soot is still being formed, reducing the local equivalence ratio and suppressing further formation of soot $[23,30]$.

Other studies have pointed to thermal enhancement of soot oxidation [13, 18, 19, 24, 31-34]. In these studies, authors argued that by targeting the post injection into regions of soot from the main injection, combustion of the post-injection fuel can also enhance oxidation of the main-injection soot by increased local temperatures.

Finally, some studies have posited that soot formation is reduced as a result of using shorter injection events; a shorter main- and a post-injection together produce less soot than a single long injection [14, 17, 35-38]. Soot reduction by this injection duration mechanism could occur in several ways. Some authors have concluded that short, close-coupled post injections do not produce any net soot [14], and so the reduction in soot from the addition of a post injection does not necessarily come from any interaction between the post jet and the main-injection mixture, but instead from simply shortening the main injection and moving the remaining fuel into a nonsooting post injection. Others have pointed to a fluidmechanical mechanism, "jet replenishment," that describes why a set of multiple shorter injections produces less soot than one long injection of the same fuel quantity [35]. Modeling results from Han et al. [35] show that during the injection, new fuel from the injector flows along the centerline of the jet and pools in the head region of the jet, where much of the soot is produced [39]. For shorter injections, the head of the jet is not replenished and the local equivalence ratio is lower, resulting in less soot formation per injection, independent of the number of injections or total amount of fuel.

Results of the current study definitively show that soot reduction can occur through the interaction of the post injection with the main-injection mixture, either through fluid-mechanical or thermal pathways, such that dividing the fuel delivery into two parts cannot be the only explanation for soot reduction with post injections. The goal of the current study is to measure the dependence of post-injection efficacy on variations in load 
(varied by changing injection duration), and to use optical diagnostics to understand more about the mechanism by which post injections reduce soot.

Previous studies have included load in parametric variations to study post-injection performance $[18,19,27,28$, 30, 32, 40]. Many of these studies varied load as part of a standard drive cycle, such as the New European Drive Cycle (NEDC) or the European Stationary Cycle (ESC) [41, 42]. In this type of study, operational parameters like load, speed, and boost are typically varied simultaneously to simulate various operating conditions representative of the drive cycle. Hence, the effects of load can be difficult to isolate from other variables.

For a given hardware setup, load can be increased in two ways: by increasing injection duration [25, 40]or by increasing injection pressure $[18,27,32]$. These two methods of varying load can have different effects on engine flows and combustion, both of which are important factors in soot production. Increasing injection duration extends the temporal span of fuel delivery while also altering the distribution of fuel in the cylinder. Alternately, increasing injection pressure alters the rate of delivery which affects the distribution of fuel in the cylinder differently than increasing injection duration. The rate of fuel/air mixing [43], the reacting jet structure [44], and soot formation [45] are affected by injection pressure. For instance, fundamental studies of soot formation in diesel jets have shown that soot formation is highly dependent on mixing upstream of the lift-off region of the reacting diesel jet [45]. Increasing the injection pressure leads to a longer lift-off length and more mixing prior to reaction, thereby reducing downstream soot formation. Considering the post injection, higher injection pressures could change the nature of the interaction between the post jet and the main-injection mixture, altering the efficacy or even the soot reduction mechanism of the post injection.

Despite these differences, previous measurements have shown that increasing load by either method has an effect on the post-injection efficacy. In general, post injections are less effective at reducing soot at higher loads for a range of injection schedules and intake conditions [18, 28, 46]. For example, results from Yun et al. [28], where load was varied by changes to injection duration, showed that at constant $\mathrm{NO}_{\mathrm{x}}$, post injections were proportionally less effective at reducing engineout soot. Post injections at 3 bar gIMEP reduced engine-out soot by $33 \%$, while post injections at 4.5 bar gIMEP reduced soot by only $16 \%$, although the absolute reduction in soot in both cases was similar. The results of the current study show a similar reduction in post-injection efficacy with increasing load, though both the proportional and absolute soot reduction are decreased with increasing load.

The remainder of this paper is organized as follows. First, we provide an overview of the optical engine facility, operating conditions, and diagnostics. Here, we take extra care to discuss the test matrix used in this study, as the method of measuring post-injection efficacy can have an impact on the interpretation of the results. Next, we present engine-out emissions data and optical results from a single-injection baseline case. This is followed by the post-injection results. Both emissions trends and analysis of the optical data are used to begin to identify the mechanism(s) by which soot is reduced by post injections and why increasing load reduces the post-injection efficacy. We conclude by offering suggestions for future avenues of investigation that may help further clarify the post-injection soot reduction mechanism.

\section{EXPERIMENTAL OVERVIEW}

The experimental overview is presented in four sections. First, details of the Sandia heavy-duty diesel engine facility are provided, followed by an overview of the operating conditions used in this study. Next, a detailed account of the test matrix is given, with a rationale for how we designed the test matrix in this study. Finally, we provide an overview of the diagnostic equipment and analysis methodologies.

\section{Optical Engine}

The experiments were conducted in a single-cylinder, direct-injection (DI), four-stroke heavy-duty diesel engine based on a Cummins $\mathrm{N}$-series production engine. The swirl ratio is 0.5 , typical of heavy-duty diesel engines similar to the N14. The layout of the engine is in Figure 1, and specifications of the engine are in Table 1.

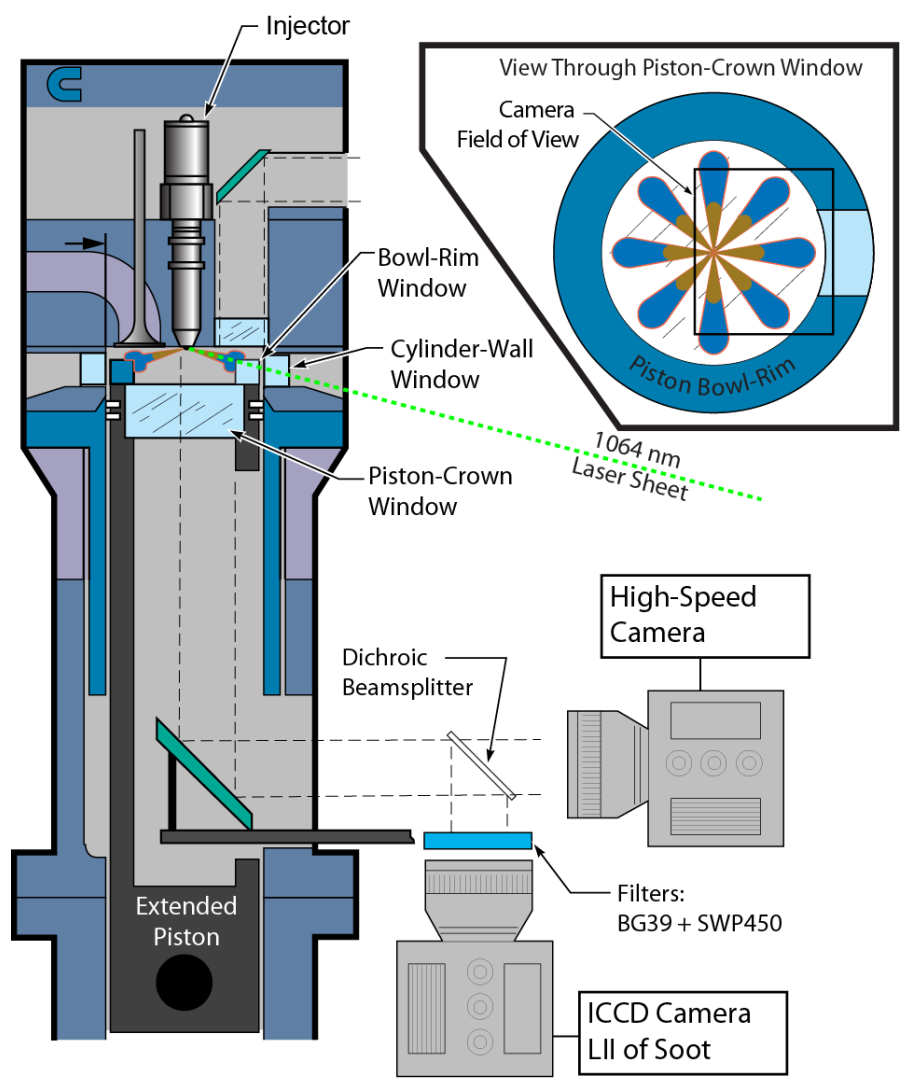

Figure 1. Experimental setup of the single-cylinder optical engine, laser configuration, and dual-camera optical system. The camera field-of-view is shown in the upper right. 
Table 1. Engine and fuel system specifications.

\begin{tabular}{|c|c|}
\hline Engine base type & Cummins N-14, DI diesel \\
\hline Number of cylinders & 1 \\
\hline Cycle & 4-stroke \\
\hline $\begin{array}{l}\begin{array}{l}\text { Number of intake } \\
\text { valves }\end{array} \\
\text {. }\end{array}$ & 2 \\
\hline $\begin{array}{l}\text { Number of exhaust } \\
\text { valves }\end{array}$ & $1 *$ \\
\hline Intake valve opening & $17^{\circ}$ BTDC Exhaust $^{\ddagger}$ \\
\hline Intake valve closing & $195^{\circ}$ ATDC Exhaust \\
\hline Exhaust valve opening & $235^{\circ}$ BTDC Exhaust $^{\ddagger}$ \\
\hline Exhaust valve closing & $27^{\circ}$ ATDC Exhaust $^{*}$ \\
\hline Combustion chamber & Quiescent, direct injection \\
\hline Swirl ratio & 0.5 (approx.) \\
\hline Bore & $139.7 \mathrm{~mm}[5.5 \mathrm{in}]$ \\
\hline Stroke & $152.4 \mathrm{~mm}[6.0 \mathrm{in}]$ \\
\hline Bowl width & $97.8 \mathrm{~mm}[3.85 \mathrm{in}]$ \\
\hline Displacement & 2.34 liters $\left[142 \mathrm{in}^{3}\right]$ \\
\hline Connecting rod length & $304.8 \mathrm{~mm}[12.0 \mathrm{in}]$ \\
\hline Piston pin offset & None \\
\hline $\begin{array}{l}\text { Geometric compression } \\
\text { ratio }\end{array}$ & $11.2: 1$ \\
\hline $\begin{array}{l}\text { Replicated compression } \\
\text { ratio }\end{array}$ & $16: 1$ \\
\hline Fuel Injector & $\begin{array}{lll}\begin{array}{l}\text { Delphi } \\
\text { duty) }\end{array} & \text { DFI-1.5 } & \text { (light } \\
\end{array}$ \\
\hline Fuel injector type & $\begin{array}{l}\text { Common-rail, solenoid } \\
\text { actuated }\end{array}$ \\
\hline Cup (tip) type & Mini-sac \\
\hline $\begin{array}{c}\text { Number of holes \& } \\
\text { arrangement }\end{array}$ & 8 , equally-spaced \\
\hline $\begin{array}{l}\text { Spray pattern included } \\
\text { angle }\end{array}$ & $156^{\circ}$ \\
\hline $\begin{array}{l}\text { Nominal } \\
\text { diameter }\end{array}$ & $0.131 \mathrm{~mm}$ \\
\hline
\end{tabular}

*In this optically accessible diesel engine, one of the two exhaust valves of the production cylinder head was replaced by a window and periscope (see Fig. 1). tAll valve timings correspond to the crank angle of the first detectable movement from fully closed.

For these experiments, the engine is outfitted with a Delphi DFI-1.5, light-duty common rail injector. The Delphi light-duty injector was chosen for its fast-acting response to close-coupled injection commands. While this injector provided reliable, close-coupled fuel delivery, there are limitations on load due to its limited capacity. The fuel is $\mathrm{n}$-heptane, which was selected for its low fluorescence upon illumination by ultraviolet (UV) laser-light. n-Heptane is commonly used as a surrogate for diesel fuels in optical engine studies that use laser diagnostics, and it is also convenient for direct comparison of experiments with computer modeling studies because of its relatively wellunderstood ignition and combustion reaction chemistry. Compared to U.S. diesel fuel, it has a slightly higher cetane number [47] and a slightly lower density, but a much lower boiling point and zero aromatics. The similarity in cetane numbers means that the autoignition characteristics of these two fuels are similar, although there may be differences in the liquid-to-vapor transition in the fuel jet as a result of the differences in boiling points. The vaporization differences are not expected to significantly impact the general soot formation characteristics. The absence of aromatics, however, will almost certainly affect the quantity of soot, but the general in-cylinder mechanisms of soot formation should be similar [48]. We view these differences in the magnitude soot formation to be an acceptable tradeoff in the use of n-heptane as the fuel to enable UV laser diagnostics. Although UV laser diagnostics are not used in this study, such diagnostics are anticipated for studies to follow, so n-heptane was chosen for consistency with future work. Details of the fuel and injection system are also in Table 1.

The engine is designed with a variety of options for optical access (Figure 1). First, an extended Bowditch piston and 45degree mirror allow visualization of the combustion chamber through the flat piston crown-window. Windows in the cylinder wall provide laser-sheet access to the spray region. In the current configuration, the laser sheet is oriented parallel the nominal axis of one of the sprays $\left(12^{\circ}\right.$ from horizontal $)$, at an elevation approximately $1 \mathrm{~mm}$ below the injector orifice for one of the fuel sprays. At this elevation, the laser sheet is as close to the nominal symmetry axis of the jet as possible without striking and potentially damaging (e.g., ablating) the injector tip. The sheet passes through two windows, one in the cylinder wall and one in the bowl rim, before striking the cylinder head. The bowl-rim window provides an intact piston-bowl boundary for the fuel spray and soot development during operation; the importance of an intact bowl-rim boundary rather than a cut-out as used in some previous studies with this engine, will be apparent in the optical results presented below. However, optical access requires several compromises to be made in engine design and operation. In particular, the compression ratio is reduced from 16:1 in the original to 11.2:1 in the optical engine as a result of the flat piston bowl and cylinder wall windows, as well as the increased ring-land crevice volume. As described in the Operating Conditions section, the intake stream is heated and boosted to achieve a "replicated" compression ratio of 16:1. Additionally, the engine is skip-fired to reduce thermal loading on the optical components. Further description of this engine and its optical measurement capability can be found in Refs. [39, 49]. 


\section{Optical Engine Diagnostics}

These tests used a variety of optical and other measurement techniques. Cylinder pressure was measured with an AVL QC34D pressure transducer with a one-quarter crank angle degree resolution. The apparent heat release rate (AHRR) was calculated from the measured cylinder pressure using standard techniques described in Ref. [50]. The AHRR profiles were calculated from the cylinder pressure profiles filtered with a low-pass Gaussian filter with a roll-off that begins at $1000 \mathrm{~Hz}$ and decreases to $1 \%$ transmission at $4200 \mathrm{~Hz}$.

Engine-out smoke was measured using an AVL 415S smoke meter. This device draws a known sample volume of engine exhaust through a filter and measures the change in reflectance (blackening) of the white filter due to accumulated soot. For conventional diesel conditions with low adsorbed hydrocarbons, the change in reflectance of the white filter is caused mostly by the accumulation of carbonaceous soot particles, which visually appears gray to black, depending on soot loading. For some LTC conditions that have high adsorbed hydrocarbons, the filter can become tinted with color $[51,52]$, which could conceivably bias the reflectivity measurement. Comparisons with other soot and adsorbed hydrocarbon measurement techniques show that even with adsorbed hydrocarbons, the reflectivity strongly correlates with the elemental carbon [51]. Furthermore, no color tinting by adsorbed hydrocarbons is discernible from visual inspection of the loaded filter paper from the current study. Hence, we expect that the reflectivity measurements in the current study are indicative of elemental carbon, which is synonymous with dry soot.

The change in reflectance for a given volume of sample gas can be quantified as a filter smoke number (FSN) [53]. Here, FSN has been converted to elemental carbon volume fraction using standard AVL correlations [53]. In each test, sampling commenced before the first fired cycle and continued well after the last fired cycle so that all the exhaust soot for each run was sampled; this amounted to a sampling time of 65 seconds, or approximately $12000 \mathrm{ml}$ of exhaust gas. Although the engine is skip fired, all data reported in this paper have been corrected to the value that would have been measured for continuously fired operation (as if the engine were not skip-fired) by correcting for the intake volume to the smoke meter, referred to as the "effective length" in the AVL calculations. The actual effective length is multiplied by a factor of the ratio of fired time to sample time, where sample time is 65 seconds and fired time is the number of fired cycles divided by engine cycles per second [54].

Two optical diagnostics were used simultaneously for visualizing in-cylinder soot development. The two techniques share the same perspective, viewing through the piston-crown window as shown in Figure 1. A dichroic beam splitter with a cutoff near $485 \mathrm{~nm}$ separated light collected from the combustion chamber, with long-wavelength light directed to the soot natural-luminosity imaging system, while the shortwavelength light was directed to the laser-induced- incandescence imaging system, both of which are described below.

Soot Natural Luminosity (soot-NL): A high-speed Phantom 7.1 complementary metal oxide semiconductor (CMOS) camera equipped with a Nikon 105-mm focal-length, f/2.8 glass lens imaged the soot-NL. Images with a resolution of $256 \times 512$ pixels and a bit depth of 4096 counts were taken at half crankangle intervals (70 microseconds at $1200 \mathrm{RPM})$. The exposure time (1-10 microseconds) and the lens aperture (f/11 to f/16) were adjusted to setting appropriate to each was a function of the intake-oxygen level.

The high-speed imaging allows for high temporal resolution over a long data set; in this study, the entire combustion event during each fired cycle was imaged using this technique. There are three shortcomings for this technique, however. First, the soot-NL signal increases strongly with soot particle temperature, which introduces a strong bias to hot soot. The bias is important both spatially (within an image) and temporally (one image to the next, such as in the later portions of the cycle when cylinder temperature decreases). As a result, lower signal in the images can either mean there is less soot in that location, or that the soot is colder. This effect also limits the dynamic range of soot detection. Less dense/cooler soot may not be detectable at the low camera gain settings required to avoid saturation of regions that are hot or of high soot density. This is a particularly important point when comparing images from different loads. The images at high-load conditions typically have a much wider range of signal intensities than lower load conditions. Second, soot-NL imaging is a line-of-sight technique, such that the threedimensional soot cloud is projected onto two dimensions. This projection introduces ambiguity when tracking structures that may be at different elevations along the line of sight. This issue is illustrated and discussed below, in the Results section. Finally, this technique images all sources luminosity from inside the combustion chamber, including soot luminosity, chemiluminescence, and other possible sources. For these operating conditions and camera exposure times, the dominant source of light is soot-NL.

Planar Laser-Induced Incandescence of Soot (soot-PLII): The fundamental output $(1064 \mathrm{~nm})$ of a Spectra-Physics Quanta-Ray single-cavity Nd:YAG laser was attenuated to 130 $\mathrm{mJ} /$ pulse and formed into a 30-mm wide, approximately 1-mm thick sheet for laser-induced incandescence of soot within the engine cylinder. As described in the Optical Engine Experiment section, the sheet was oriented to probe soot along the approximate symmetry plane of one of the fuel jets. Using the fundamental output at $1064 \mathrm{~nm}$ avoids fluorescence of large PAH species, so that only solid soot particles are targeted [55]. As described in previous studies [39], the laser-heated soot emits more strongly at shorter wavelengths than the combustion-heated soot, so the soot-PLII emission was spectrally filtered to shorter wavelengths to improve the signalto noise ratio. Soot-PLII emission was collected at wavelengths shorter than $450 \mathrm{~nm}$ with an intensified Princeton Instruments 
PI-MAX 3 camera with a resolution of $1024 \times 1024$, a gate time of $15 \mathrm{~ns}$, and at $50 \%$ of maximum gain. Two filters, BG39 and WPF450 rejected longer-wavelength emission. PLII data were limited to one frame per cycle, due to repetition-rate constraints of both the laser and camera system.

These two optical techniques are used together because of the complementary information that they provide. The sootPLII technique helps to resolve the ambiguity in the soot-NL images due to projection onto two dimensions and due to bias toward hot/dense soot. For the soot-PLII technique, there is no spatial ambiguity of the soot signal in either regard. The laser sheet is only located along one plane, the jet axis, localizing the soot-PLII signal and allowing us to use the soot-PLII images as a reference for understanding one line-of-sight integrated sootNL image per cycle. Additionally, the LII signal from soot laser-heated to its vaporization temperature is almost completely independent of the original combustion-heated soot temperature. Hence, in the absence of signal trapping and other secondary effects, the LII signal is a function of soot concentration only [56]. We use the soot-PLII technique in this study to eliminate ambiguities in the soot-NL imaging and support the conclusions derived from the soot-NL data.

\section{Operating Conditions}

Engine operating conditions are summarized in Table 2. The intake stream is pressurized and heated by a compressor and electrical air heater. EGR is simulated by adding nitrogen $\left(\mathrm{N}_{2}\right)$ to the intake air stream. Diluting the intake stream with nitrogen alone, without water and carbon dioxide, yields a lower heat capacity than real EGR, such that the flame temperatures are higher for a given intake-oxygen level (also see [57]). At all EGR conditions, the intake-charge density, and hence the charge density at TDC, is intentionally held constant to maintain similar spray penetration as EGR is varied. As a result, the global equivalence ratio increases as EGR is increased; the global equivalence ratio is calculated for the

Table 2. Engine operating conditions.

\begin{tabular}{|l|l|}
\hline Engine Speed & $1200 \mathrm{RPM}^{*}$ \\
\hline Engine Load Range & $3-8 \mathrm{bar}^{*} \mathrm{gIEP}^{\dagger}$ \\
\hline Intake $\mathrm{O}_{2}$ & $12.6,15,18,21 \%$ \\
\hline Fuel Pressure & $1200 \mathrm{bar}$ \\
\hline TDC Motored Density & $16.6 \mathrm{~kg} / \mathrm{m}^{3}$ \\
\hline TDC Motored Temperature & $900 \mathrm{~K}$ \\
\hline Intake Pressure & $161 \mathrm{kPa}$ \\
\hline Intake Temperature Ratio & $108^{\circ} \mathrm{C}$ \\
\hline $\begin{array}{l}(16: 1 \quad \text { Compression } \\
\text { Intake Pressure })\end{array}$ & $99 \mathrm{kPa}(\mathrm{abs})$ \\
\hline $\begin{array}{l}(16: 1 \quad \text { Compression Ratio } \\
\text { Intake Temperature) }\end{array}$ & $41^{\circ} \mathrm{C}$ \\
\hline
\end{tabular}

* At this speed, each crank angle degree (CAD) is 139 microseconds in duration.

${ }^{\dagger}$ gIMEP = Gross Indicated Mean Effective Pressure, calculated using indicated work done during compression and expansion strokes only. replicated 16:1 compression-ratio cycle and ranges are reported in Table 3.

The choice of intake-oxygen levels was guided by industry practice with regard to EGR levels commonly used to meet emissions regulations. $18 \% \mathrm{O}_{2}$ was chosen as the baseline point because this range of EGR (20-32\%) is commonly used to meet 2010 particulate and $\mathrm{NO}_{\mathrm{x}}$ regulations [55] with the use of both urea-based selective catalytic reduction (SCR) and diesel particulate filter (DPF) after-treatment systems [58]. All the optical analysis in this work is for $18 \%$ intake oxygen. $12.6 \%$ intake oxygen is approximately the level that would be required to meet the 2010 particulate and $\mathrm{NO}_{\mathrm{x}}$ regulations without the use of aftertreatment systems [58]. $15 \% \quad \mathrm{O}_{2}$ is a common intake-oxygen level for low-temperature combustion (LTC) conditions [6]. At these conditions, diluted intake charge and non-traditional injection timings are used to reduce $\mathrm{NO}_{\mathrm{x}}$ and soot emissions [5]. Finally, 21\% $\mathrm{O}_{2}$ was used as a reference representing operation without EGR.

Across the whole span of low-load conditions investigated here, the intake charge density is held constant at a level that corresponds to naturally aspirated conditions. The charge

Table 3. Engine operating test matrix for sweep in load.

\begin{tabular}{|c|c|c|c|c|c|c|}
\hline $\begin{array}{l}\% \\
\mathbf{O}_{2}\end{array}$ & $\begin{array}{c}\% \\
\text { EGR }\end{array}$ & $\begin{array}{c}\text { Global } \\
\text { Equivalence } \\
\text { Ratio } \\
\end{array}$ & $\begin{array}{c}\operatorname{SOI1}_{C} \\
{[\mathrm{CAD}]}\end{array}$ & $\begin{array}{c}\text { DOI1 }_{C} \\
{[\mu s e c]} \\
([\mathrm{CAD}]) \\
\end{array}$ & $\begin{array}{l}\text { SOI2 }_{C} \\
{[\mathrm{CAD}]}\end{array}$ & 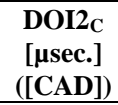 \\
\hline 21 & 0 & $0.2-0.46$ & 347 & $\begin{array}{c}1350- \\
3350 \\
(9.7-24.1) \\
\end{array}$ & - & - \\
\hline 21 & 0 & $0.23-0.31$ & 347 & $\begin{array}{c}1550 \\
(11.1) \\
\end{array}$ & 366 & $\begin{array}{l}300-600 \\
(2.2-4.3)\end{array}$ \\
\hline 21 & 0 & $0.28-0.43$ & 347 & $1950(14)$ & 366 & $\begin{array}{c}300-1000 \\
(2.2-7.2)\end{array}$ \\
\hline 18 & $\begin{array}{l}20- \\
32\end{array}$ & $0.24-0.44$ & 347 & $\begin{array}{c}1350- \\
2750 \\
(9.7-19.8) \\
\end{array}$ & - & - \\
\hline 18 & $\begin{array}{c}20- \\
32 \\
\end{array}$ & $0.27-0.36$ & 347 & $\begin{array}{c}1550 \\
(11.1) \\
\end{array}$ & 366 & $\begin{array}{l}300-600 \\
(2.2-4.3)\end{array}$ \\
\hline 18 & $\begin{array}{l}20- \\
32 \\
\end{array}$ & $0.33-0.47$ & 347 & $1950(14)$ & 366 & $\begin{array}{c}300-700 \\
(2.2-5)\end{array}$ \\
\hline 18 & $\begin{array}{c}20- \\
32 \\
\end{array}$ & $0.38-0.5$ & 347 & $\begin{array}{l}2350 \\
(16.9) \\
\end{array}$ & $368^{*}$ & $\begin{array}{l}200-500 \\
(1.4-3.6) \\
\end{array}$ \\
\hline 15 & $\begin{array}{l}35- \\
48\end{array}$ & $0.28-0.50$ & 347 & $\begin{array}{c}1350- \\
2550 \\
(9.7-18.3) \\
\end{array}$ & - & - \\
\hline 15 & $\begin{array}{c}35- \\
48 \\
\end{array}$ & $0.32-0.43$ & 347 & $\begin{array}{c}1550 \\
(11.1) \\
\end{array}$ & 366 & $\begin{array}{l}300-600 \\
(2.2-4.3) \\
\end{array}$ \\
\hline 15 & $\begin{array}{c}35- \\
48 \\
\end{array}$ & $0.39-0.5$ & 347 & $1950(14)$ & 366 & $\begin{array}{l}300-600 \\
(2.2-4.3)\end{array}$ \\
\hline $\begin{array}{c}12 . \\
6\end{array}$ & $\begin{array}{l}40- \\
57\end{array}$ & $0.34-0.68$ & 347 & $\begin{array}{c}1350- \\
2950 \\
(9.7-21.2) \\
\end{array}$ & - & 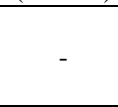 \\
\hline $\begin{array}{c}12 . \\
6\end{array}$ & $\begin{array}{c}40- \\
57 \\
\end{array}$ & $0.38-0.52$ & 347 & $\begin{array}{c}1550 \\
(11.1)\end{array}$ & 366 & $\begin{array}{l}300-600 \\
(2.2-4.3)\end{array}$ \\
\hline $\begin{array}{c}12 . \\
6 \\
\end{array}$ & $\begin{array}{l}40- \\
57 \\
\end{array}$ & $0.57-0.62$ & 347 & 1950 (14) & 366 & $\begin{array}{l}300-650 \\
(2.2-4.7) \\
\end{array}$ \\
\hline
\end{tabular}

*SOI2 $2_{\mathrm{C}}$ was necessarily delayed slightly for the longest main-injection schedule to assure consistent and stable separation between main and post injections. While this shift does not adhere strictly to the CSOI definition, this injection schedule still results in post-injection heat release at very similar timings to that of the shorter two main-injection duration schedules (see Figure 3), thereby effectively achieving the CSOI intent. 
density is intentionally held constant so that changes in jet penetration are affected by injection duration, and not by varying boost levels at different loads. Increasing boost with increasing load, as might be done to maintain a constant global equivalence ratio, would affect jet penetration, but for this more fundamental study, we intentionally avoided this complicating factor to simplify interpretations of the results. In addition, the naturally aspirated boost levels are similar to the low-boost conditions in production engines at low load, and are directly comparable to the low-load operating conditions that served as part of the database to support Dec's conceptual model for conventional diesel combustion [39].

\section{Test Matrix}

In this study, post-injection efficacy is measured as a function of load at four intake-oxygen levels. Table 3 provides an overview of the operating conditions in this study. Although emissions results for four intake-oxygen levels are presented, the detailed analysis in this work focuses on the load sweep for the $18 \%$ intake-oxygen conditions. Our previous work [46] has shown that both the engine-out smoke emissions and in-cylinder soot behavior of the $18 \% \mathrm{O}_{2}$ baseline condition are similar to those of the $21 \% \mathrm{O}_{2}$ condition - we refer to these as the "highoxygen conditions." For the "low-oxygen conditions" at $15 \%$ and $12.6 \% \mathrm{O}_{2}$, the engine-out smoke emissions and in-cylinder soot behavior are quite different. We present some general engine-out soot results at these low-oxygen conditions for reference only, but it is beyond the scope of the current paper on load effects to discuss in detail the intake-oxygen effects on in-cylinder behavior of post injections. Instead, we focus here on the $18 \%$ intake-oxygen condition, which is most representative of current production diesel technology. For a more thorough discussion of our in-cylinder results for both high- and low-oxygen conditions, see Ref. [46].

The test matrix contains two types of injection schedules a single-injection schedule, and a main- plus post-injection schedule. To establish consistent terminology, we refer to injection schedules with only one injection as "single-injection" schedules. Additionally, we refer to injection schedules with two injections, a main injection and a post injection, as "mainplus post-injection" schedules. At equivalent loads, a singleinjection condition has a longer duration of injection (DOI) than the main injection of a main- plus post-injection condition.

In the post-injection duration sweeps to follow in the results section, the main injection duration is held constant as the post-injection duration is varied. This means that at equivalent loads, a single-injection condition has a longer injection duration than the main injection of a main- plus postinjection condition. This method of studying post-injection efficacy helps to isolate the fluid-mechanic aspects of soot reduction via post injections. By keeping the main-injection constant and varying post-injection duration only, the "initial condition" for the post injection can be held constant regardless of post-injection duration. This approach contrasts with a constant-load or a typical "split injection" scheme where a constant fuel quantity would require the main-injection duration to shorten as the post-injection duration increased $[59,60]$.

The experimental methodology presented in Table 3 was chosen from three possible options for testing the effect of load on post-injection efficacy. Given that the baseline load is varied by changing the main-injection duration, there is no way to systematically vary only one injection or combustion variable at once. Trade-offs between maintaining certain chemical and fluid-mechanic properties versus allowing them to vary must be accepted in this type of investigation.

Four variables were identified as "knobs" that could be varied to test the effect of load on post-injection efficacy: start of the main injection (SOI1), end of the main injection (EOI1), start of the post injection (SOI2), and injection dwell (time between EOI1 and SOI2). In this study, we have kept SOI1 and SOI2 constant, allowing EOI1 and injection dwell to vary between the three load conditions, referred to as the "constant SOI" (CSOI) approach. A detailed explanation of each possible test matrix and associated tradeoffs is provided in Appendix A.

\section{RESULTS}

Discussion of the results begins with injection rate and engine heat-release. Next, an overview of the single-injection cases provides the next baseline for the next post-injection cases discussed next. In both sections, engine-out soot measurements as well as optical results from soot-PLII and soot-NL imaging are presented.

\section{Engine Operation Data}

Measured injection-rate profiles for the CSOI approach at three load conditions are shown in Figure 2. These profiles were derived from spray impingement (momentum) measurements using a Kistler 9215 force transducer connected to a Kistler 5004 charge amplifier. Force data were collected at $140 \mathrm{kHz}$ over the span of 200 injections from one hole at atmospheric back pressure, and total fuel mass from all eight holes was measured to derive a mass rate of injection [61]. The profiles are averaged over the 200 injections and low-pass filtered (Gaussian roll-off at $10 \mathrm{kHz}$ ) to remove ringing at the natural frequency of the transducer assembly.

In plots $\mathrm{a}, \mathrm{b}$ and $\mathrm{c}$ of Figure 2, the shape of the main injection was similar across all three main-injection durations. The small fluctuations in the mass rate of injection preceding the start of the main injection are an artifact of the filtering (they disappear at higher roll-off frequencies). The initial rise also has a small "spike" just above $20 \mathrm{mg} / \mathrm{s}$. This spike was determined to be a real component of the data, not a result of the filtering process (the spike remains at higher filter frequencies). Additionally, the main-injection profile remains essentially unchanged even when a post injection is added.

For post injections with commanded durations of injection $\left(\mathrm{DOI} 2_{\mathrm{C}}\right.$ ) from 300 to 700 microseconds, the shape, duration, and magnitude of the post injection rate profile change for each increasing post-injection duration. The measured (actual) postinjection duration increases by approximately 1 CAD, or 139 

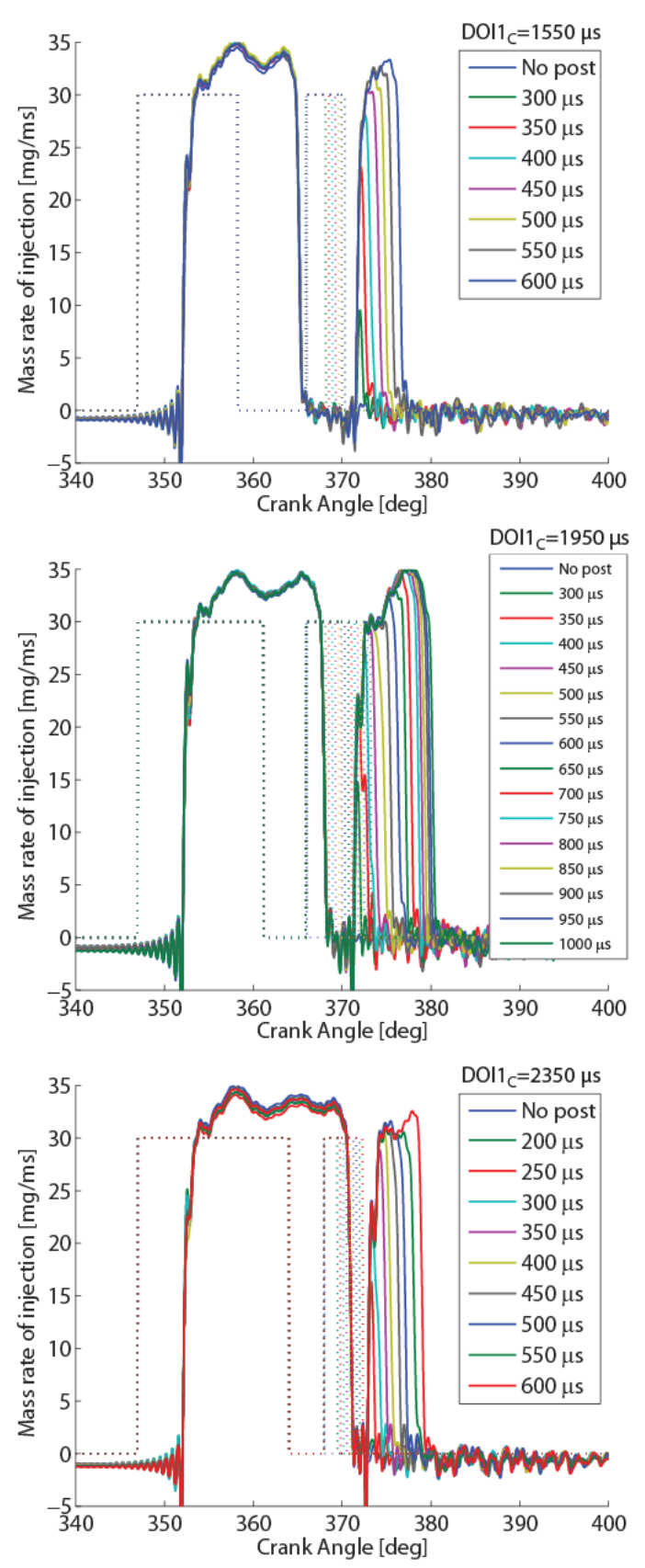

Figure 2. Mass rate-of-injection commands (dotted lines) and profiles (solid lines) over a range of DOI2 $_{C}$ with SOI1 $_{C}=347$ CAD for a) $D O I 1_{C}=1550$ microseconds and SOI2 ${ }_{C}=366$ CAD, b) DOI1 ${ }_{C}=1950$ microseconds and SOI $2_{C}=366 \mathrm{CAD}$, and c) $\mathrm{DOI} 1_{\mathrm{C}}=2350$ microseconds and $\mathrm{SOI}_{\mathrm{C}}=368 \mathrm{CAD}$.

microseconds, for each step change of the commanded injection duration by 50 microseconds. For post injections with DOI $2_{C}$ greater than 700 microseconds, the height and characteristic rate-shape stays relatively constant, and the measured (actual) post-injection duration change is approximately the same as the 50 microsecond change in the commanded duration.

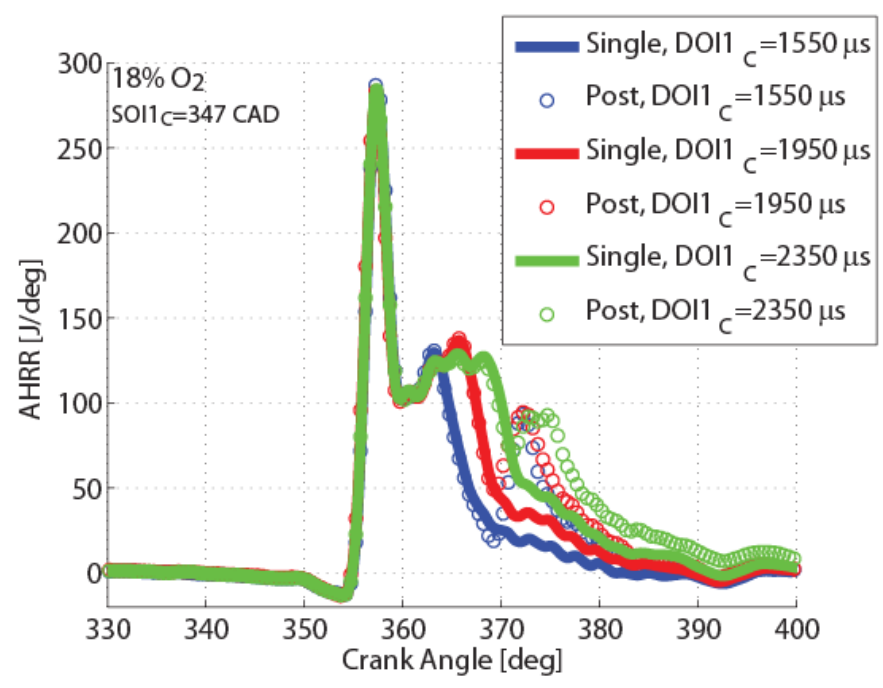

Figure 3. Apparent heat release rate for three baseline loads, DOI1 ${ }_{\mathrm{C}}=1550$ microseconds with $\mathrm{DOI} 2_{\mathrm{C}}=500$ microseconds (blue), DOI $1_{\mathrm{C}}=1950$ microseconds with DOI $2_{C}=500$ microseconds $($ red $)$, and DOI $_{C}=2350$ microseconds with $\mathrm{DOI} 2_{\mathrm{C}}=300$ microseconds (green) for both single (solid line) and main- plus post-injection (circles) schedules at $18 \% \mathrm{O}_{2}$ and $\mathrm{SOI}_{\mathrm{C}}=347 \mathrm{CAD}$.

The representative AHRR profiles in Figure 3 show similar features among the three loads. Each profile displays a distinct premixed burn during the injection event. The premixed burn is followed by a mixing-controlled combustion event, which is less prominent in the heat release analysis because of the relatively low-load conditions. The injection schedules with post injections also include a third peak in the AHRR profile due to combustion of the post-injection fuel at approximately 372 CAD.

\section{Single-Injection Baseline}

Engine-out soot measurements at four intake-oxygen content conditions indicate that soot emissions increase with load for a single-injection schedule, as shown in Figure 4. Here, the load was varied by changing the commanded duration of injection $\left(\mathrm{DOI} 1_{\mathrm{C}}\right)$ starting from 1350 microseconds in 200 microsecond increments (single injections only). Also recall that here, the boost is held constant with increasing load to avoid the confounding effect of ambient density on jet penetration and the associated complications in the interpretation of results. Under typical production engine conditions, boost would increase with load, which would likely affect the soot trends to some degree.

Engine-out soot emissions display a different functional dependence on load at each intake-oxygen level. For highoxygen conditions, $21 \%$ and $18 \% \mathrm{O}_{2}$, the engine-out soot increases linearly with load over the range investigated; the curve-fits for these two data sets in Figure 4 are linear. While the increase is linear, it is not proportional due to the fact that the y-intercept of the data is not at zero. For low-oxygen conditions, $15 \%$ and $12.6 \% \mathrm{O}_{2}$, however, the engine-out soot 


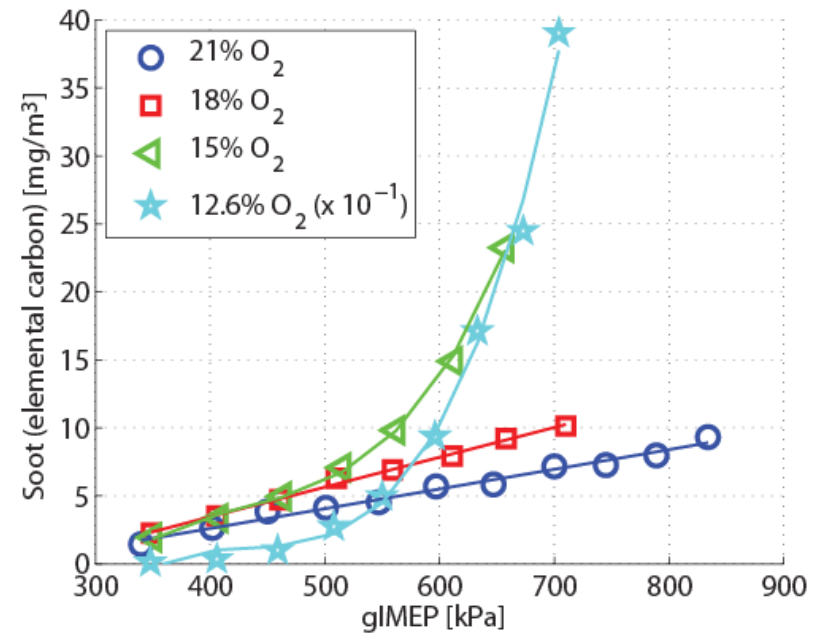

Figure 4. Engine-out soot for single-injection operation at a variety of DOI1 $_{C}$ at four intake-oxygen levels and SOI1 $_{\mathrm{C}}=347$ CAD.

increase nonlinearly with load; the curve-fits for these two data sets in Figure 4 are cubic. This is an example of one way that engine-out smoke trends are characteristically different between high- and low-oxygen conditions.

As discussed above, we will focus on results from the $18 \%$ intake-oxygen case to investigate the effect of load on postinjection efficacy. Figure 5 shows the three single-injection conditions we will use for comparison in this study.

Here, injection durations of $\mathrm{DOI} 1_{C}=1550,1950$, and 2350 microseconds serve as baseline points for comparison. Figure 6 shows the progression of soot luminosity, measured by soot-NL imaging, after the end of injection (AEI) for a single-injection schedule at three loads, as indicated in Figure 5. Each image is the ensemble average of 20 images, and the relative intensity of each image set as compared to those at other injection durations is shown in the top-left corner of each image. The images at each condition have been obtained and/or post-processed to have similar printed image intensities; this includes taking the images at different F-stops and exposure times as well as some post processing. For example, "x15" indicates that the image has been made 15 times brighter as compared to an image with " $x 1$ " to make them appear similar in the printed images. Additionally, Figure 7 shows example instantaneous soot-PLII images at the same timings as the ensemble-average images in Figure 6. Comparison of the signal intensity distributions in Figure 6 and Figure 7 show that the general signal evolution in the soot-NL images is mirrored in the soot-PLII images. The similarity of the intensity distributions for the two techniques indicates that the large-scale changes in the soot-NL signal described below are due to changes in local soot concentration, and not due to a reduction of soot temperature.

At the end of injection at all three $\mathrm{DOI}_{\mathrm{C}}$, the first row of Figure 6, the jet has impinged on the bowl wall and soot has formed in the recirculation regions on either side of the jet centerline. As the injection duration increases, the size of these

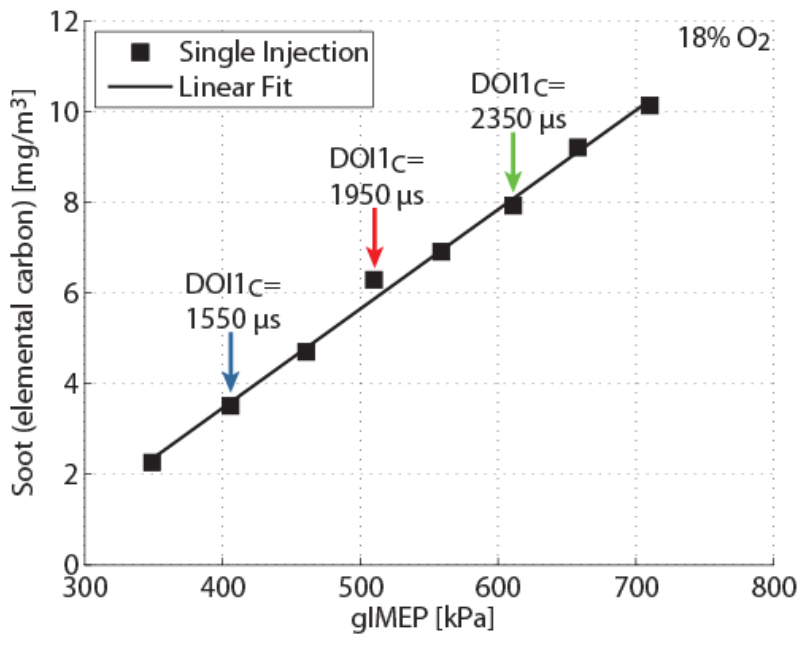

Figure 5. Engine-out soot for single-injection operation at a variety of DOI1 ${ }_{C}$ with $18 \% \mathrm{O}_{2}$ and $\mathrm{SOI1}_{\mathrm{C}}=347 \mathrm{CAD}$.

regions grows since more soot and combustion products are recirculated. Along the jet centerline, the soot structure is typical of that of a conventional diesel jet [45]. The first downstream location of soot luminosity shortens as the load $\left(\mathrm{DOI} 1_{\mathrm{C}}\right)$ increases; soot forms approximately $15 \mathrm{~mm}$ downstream of the injector at $\mathrm{DOI} 1_{\mathrm{C}}=2350$ microseconds, but $25 \mathrm{~mm}$ downstream at $\mathrm{DOI} 1_{\mathrm{C}}=1550$ microseconds. This difference is likely driven by the higher cylinder temperature and pressure at the end of injection for the longer injection, which shortens the lift-off length and enhances soot formation in the diesel jet [43].

After the end of injection, the upstream edge of the soot moves along the jet centerline towards the bowl wall, while the recirculation regions on either side of the centerline continue to grow. At $6^{\circ} \mathrm{AEI}$, the centerline soot has receded past the radial extent of the recirculation zones, creating a large zone along the jet centerline that has very little soot. By $9^{\circ} \mathrm{AEI}$, there is hardly any soot between the two recirculation regions for the two lower loads, although some soot still remains in this region near the bowl wall at the highest load. This apparent rapid oxidation of soot along the jet centerline is likely the result of end-ofinjection mixing $[62,63]$ that entrains fresh oxygen into the soot in the jet, enhancing oxidation in the jet column all the way to the bowl wall [64]. The effect of swirl is also noticeable at the latest crank angle, as the soot clouds have convected counter-clockwise relative to the cylinder axis (upwards in these images).

The difference in the soot distribution at $9^{\circ}$ AEI between the three load cases is driven by the quantity of fuel injected in each case. In the high load case, a large quantity of fuel is injected, and the combustion products, including soot, spread over a greater spatial extent of the bowl, including deeper into bowl and closer to the firedeck. Preliminary data (not shown here) from a follow-on study with soot-PLII imaging in several planes at different heights relative to the firedeck indicate that 

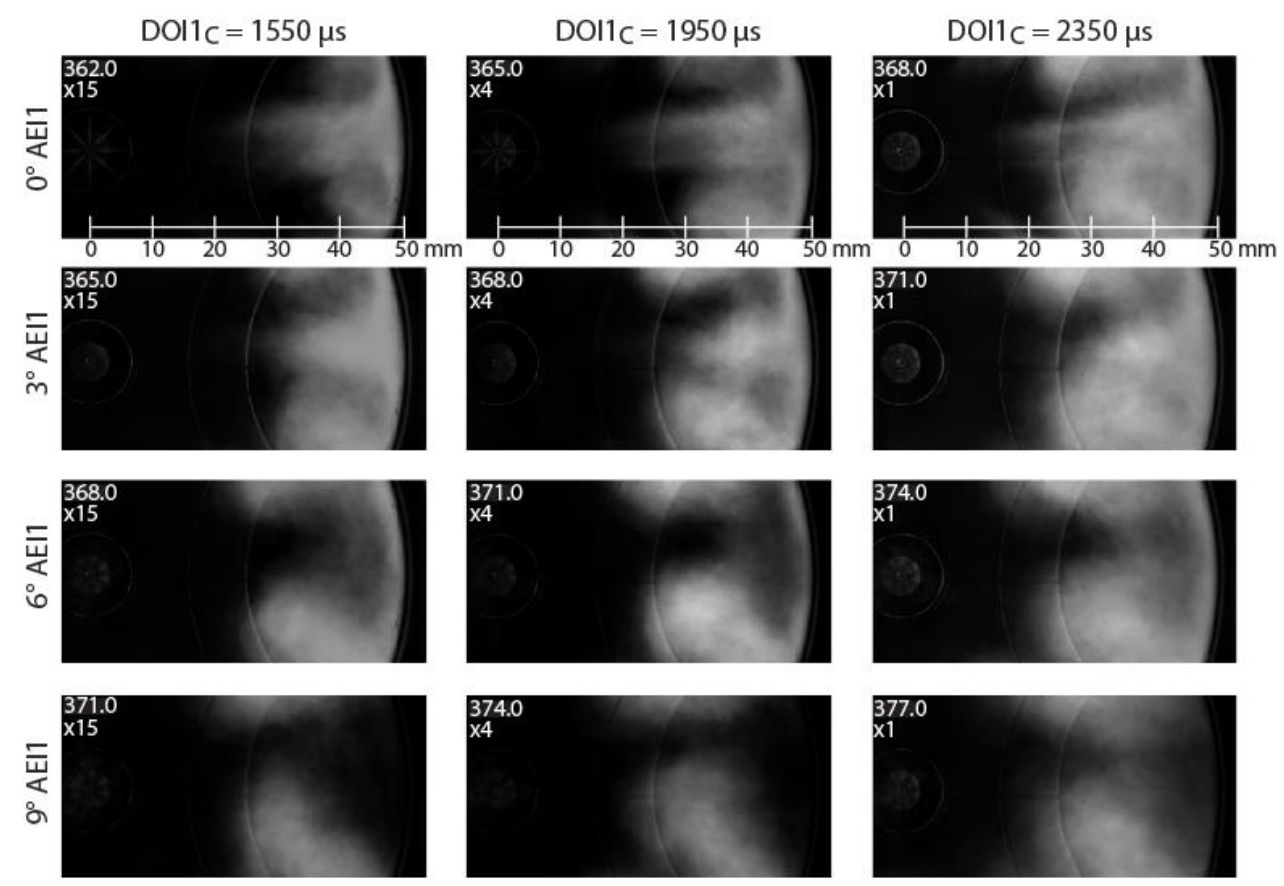

Figure 6. Ensemble-average soot-NL imaging of single-injection schedules at three loads (columns) and four timings after the end of injection (rows) with $18 \% \mathrm{O}_{2}$ and $\mathrm{SOI}_{\mathrm{C}}=347 \mathrm{CAD}$. Crank-angle timing (top) and image intensity scaling (bottom) are in the upper left corner of each image.
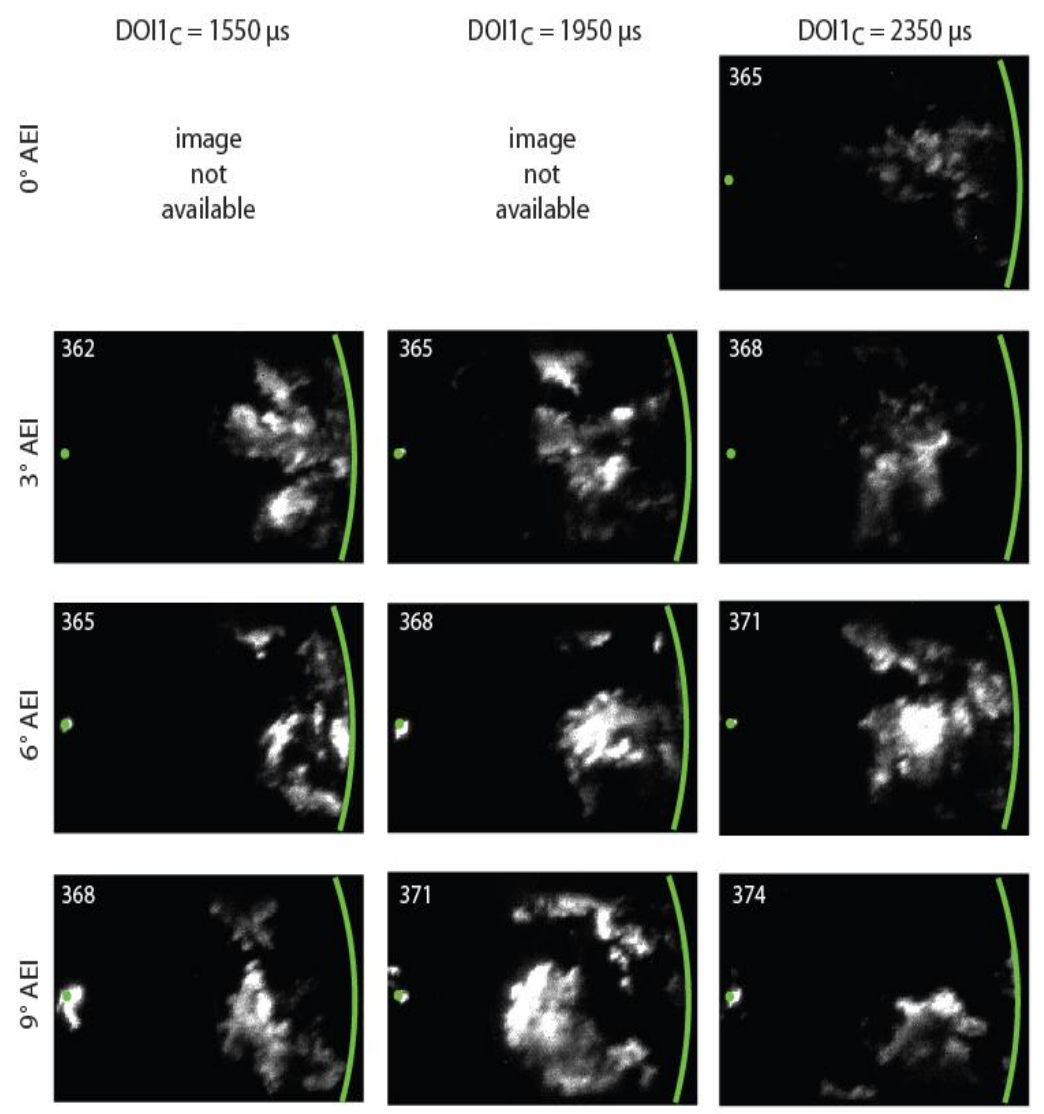

Figure 7. Instantaneous soot-PLII images of single-injection schedules at three loads (columns) and four timings after the end of injection (rows) with $18 \% \mathrm{O}_{2}$ and $\mathrm{SOI} 1_{\mathrm{C}}=347 \mathrm{CAD}$. The green dot at the left is the injector location and green line on the right is the bowl wall location. Crank-angle timing is in the upper left corner of each image. 
much of the soot spreads downwards into the flat-bottomed bowl after impinging on the bowl wall. Different piston bowl geometries currently not reflected in this optical engine could result in different flow patterns and soot distributions.

Comparison of the ensemble-averaged soot-NL images and the instantaneous soot-PLII images at the latest crank angles indicates that what soot is left along the wall, particularly at the high load case $\left(\mathrm{DOI} 1_{\mathrm{C}}=2350\right.$ microseconds) is likely below the jet axis, where the laser for LII bisects the jet. Almost no LII signal is apparent near the bowl wall (far right side of images) in any of the soot-PLII images at this crank angle (including those not shown here), indicating that the soot and products from the long injection have convected downward as the piston descends (some soot may also move upward toward the firedeck and squish region).

If a post injection were present, it would have started and ended approximately at the two latest timings, $6{ }^{\circ} \mathrm{AEI}$ and $9^{\circ} \mathrm{AEI}$ respectively, for each of the minimum-soot cases discussed in the next section. Differences in the soot spatial distribution and temporal evolution during these times serve as changes to the "initial conditions" of the main-injection soot distribution for the post injection. In particular, increases in load $\left(\mathrm{DOI} 1_{\mathrm{C}}\right)$ lead to increases in the amount of soot in the cylinder as well as its spatial extent, particularly along the jet centerline and near the bowl wall, as described above.

\section{Post-Injection Results}

Post injections were added to each of the three baseline load points in Figure 5 to study the effect of load on postinjection efficacy. These tests sweep the post-injection duration while holding the duration of the main injection constant. In this way, we are able to measure the "most effective" postinjection duration and understand more about the fluid mechanic interactions between post injections of varying durations with the same residual main-injection mixture for each baseline load.

Figure 8 shows the engine-out soot for main- plus postinjection (open symbols) as compared to the single-injection baseline (filled squares). For each main-injection duration, the post-injection trend with increasing $\mathrm{DOI} 2_{\mathrm{C}}$ is similar: the engine-out soot initially decreases, reaches a minimum, and subsequently increases as post-injection duration increases. After the soot minimum, the slope of the engine-out soot rise with increasing load is steeper than for the baseline single injection. Hence, for very long duration post injections, the addition of a post injection results in the same or higher engineout soot as compared to the single-injection baseline at the same load. Here, the point at which the post injection becomes detrimental to engine-out soot is termed the "cross-over point."

There are two ways of quantifying the effectiveness of the post injection for reducing engine-out soot for this type of data set: comparison to a single injection at the same load (but with the main injection duration shorter than the single-injection duration), or comparison to a single injection of the same duration as the main injection (but at a lower load). The

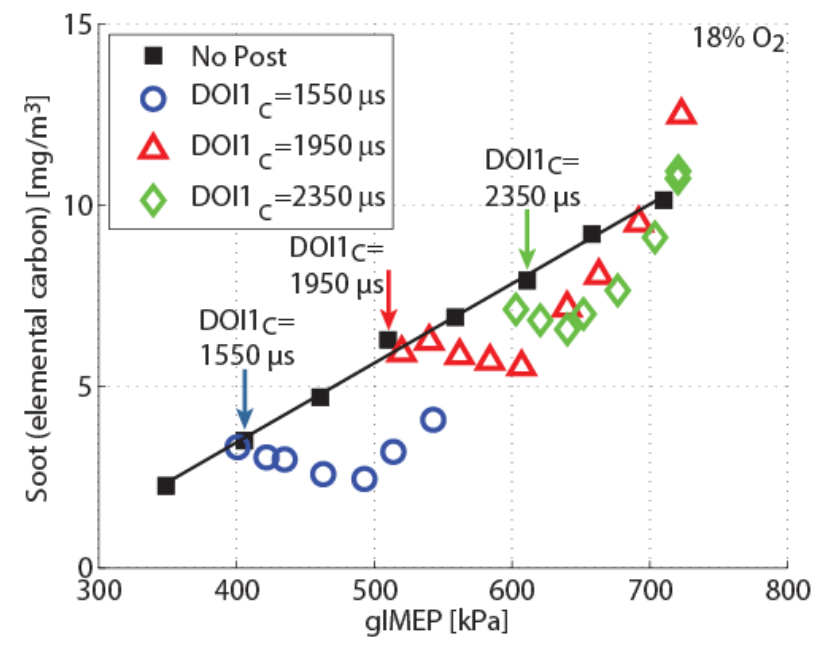

Figure 8. Engine-out soot for main- plus post-injection operation at three DOI1 $_{C}$ with $18 \% \quad O_{2}$ and SOI1 $_{C}=347$ CAD.

constant-load perspective is relevant for practical engine operation, where it is desirable to achieve a particular load point. The constant main-injection perspective is relevant for more fundamental fluid-mechanical considerations, where it is desirable to maintain a constant in-cylinder environment at the start of the post injection (e.g., penetration of the main-injection jet). Both perspectives are discussed in the following paragraphs.

From the constant-load perspective, the post injections become less effective at reducing soot compared to a single injection as the baseline load (main-injection duration) increases. The reduction of engine-out soot at constant load for the three post-injection duration sweeps in Figure 8 are shown on either a percentage (top) or an absolute (bottom) basis in Figure 9. The post injections are most effective at the lowest baseline load (DOI $1_{C}=1550$ microseconds), with a maximum soot reduction of approximately $55 \%$ or $3.0 \mathrm{mg} / \mathrm{m}^{3}$ for a postinjection duration of $\mathrm{DOI} 2_{\mathrm{C}}=500$ microseconds compared to a single injection at the same load. The maximum engine-out soot reductions for each of the subsequent increases in baselineload are $31 \%$ or $2.4 \mathrm{mg} / \mathrm{m}^{3}$ at DOI $1_{\mathrm{C}}=1950$ microseconds and DOI $2_{C}=500$ microseconds, and $25 \%$ or $2.1 \mathrm{mg} / \mathrm{m}^{3}$ at DOI $1_{C}=2350$ microseconds and DOI $2_{C}=300$ microseconds.

The trends in percentage reduction in post-injection efficacy (versus a single injection at the same load) with load are somewhat consistent across the four intake-oxygen conditions tested. Figure 10 (top) shows the maximum percentage reduction in engine-out soot by main- plus postinjections compared to a single injection at the same load for four intake-oxygen levels. In general, the post-injection efficacy on a percentage basis decreases with increasing load.

The results of absolute engine-out soot reduction are not as consistent, however. Figure 10 (bottom) shows the maximum absolute engine-out soot reduction versus a single injection at the same load for four intake-oxygen levels. At the two high- 

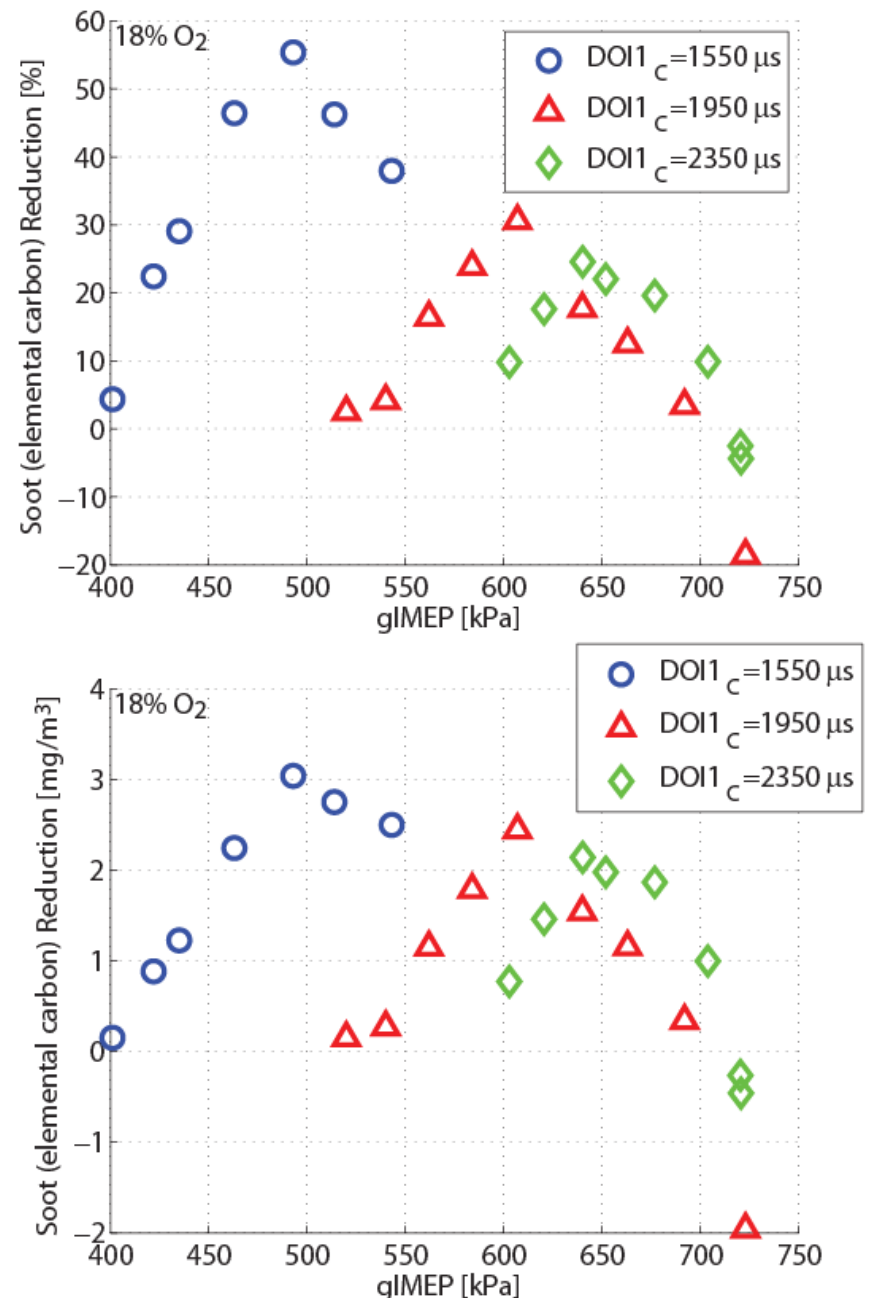

Figure 9. Percentage (top) and absolute (bottom) reduction in engine-out soot compared to a single injection at the same load for main- plus post-injection operation at three DOI1 $\mathrm{C}$ with $18 \% \mathrm{O}_{2}$ and $\mathrm{SOI1}_{\mathrm{C}}=347 \mathrm{CAD}$.

oxygen conditions ( $18 \%$ and $21 \% \mathrm{O}_{2}$ ), the absolute postinjection efficacy is relatively insensitive to load. Conversely, at the low-oxygen conditions (12.6\% and 15\%), the absolute post-injection efficacy increases with increasing baseline load. The difference between the percentage and absolute scales is driven by the single-injection trends of engine-out soot versus load (injection duration), as discussed in Figure 4. The lowoxygen trends increased nonlinearly and very drastically with increasing load, while the high-oxygen conditions were relatively linear.

The other method of quantifying post-injection efficacy is with respect to the main injection. In this calculation, the soot reduction with a post injection is calculated as compared to the main injection only (no post injection), which is at a lower load. Figure 11 shows the percentage (top) and absolute (bottom) reduction from the main-injection level, respectively, of engineout soot for the three post-injection duration sweeps at $18 \% \mathrm{O}_{2}$.
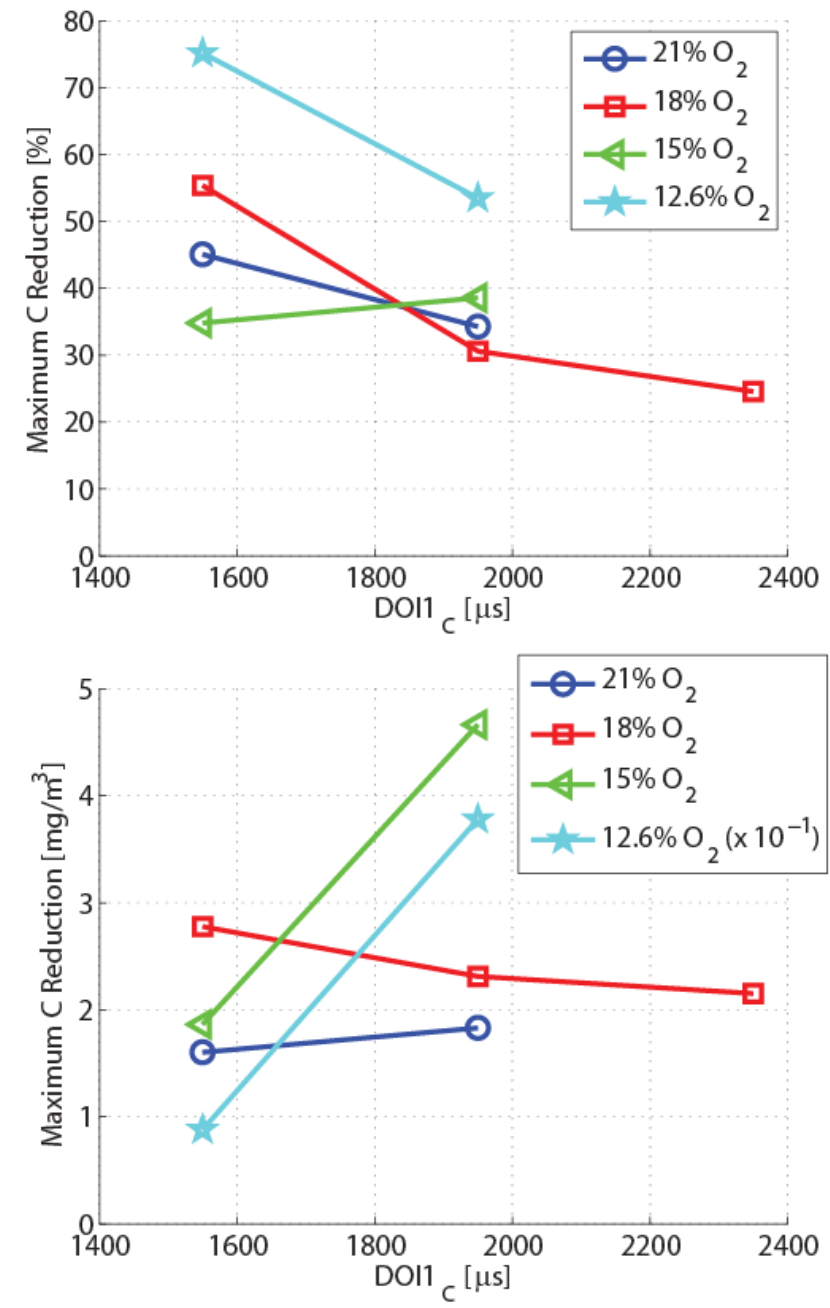

Figure 10. Maximum percentage (top) and absolute (bottom) reduction in engine-out soot for a main- plus postinjection schedule compared to a single injection at the same load for three main-injection durations (loads) and four intake-oxygen levels.

The main- plus post-injection efficacy relative to the main injection without a post exhibits different results for percentage versus absolute soot reduction. On a percentage basis, the lowload conditions can result in more effective post injections than at high loads (Figure 11, top) over a range of post-injection durations from approximately 300 to 500 microseconds. At longer post-injection durations, the percentage reduction is negative - indicating higher soot levels when a post injection is used. On an absolute basis, the maximum post-injection engine-out soot reductions are very similar at all loads (Figure 11, bottom). The differences in the two perspectives will be discussed further with respect to the optical data later in this section.

The final injection-schedule parameter with a strong dependence on load is the cross-over post-injection duration; this is the post-injection duration at which the post injections 

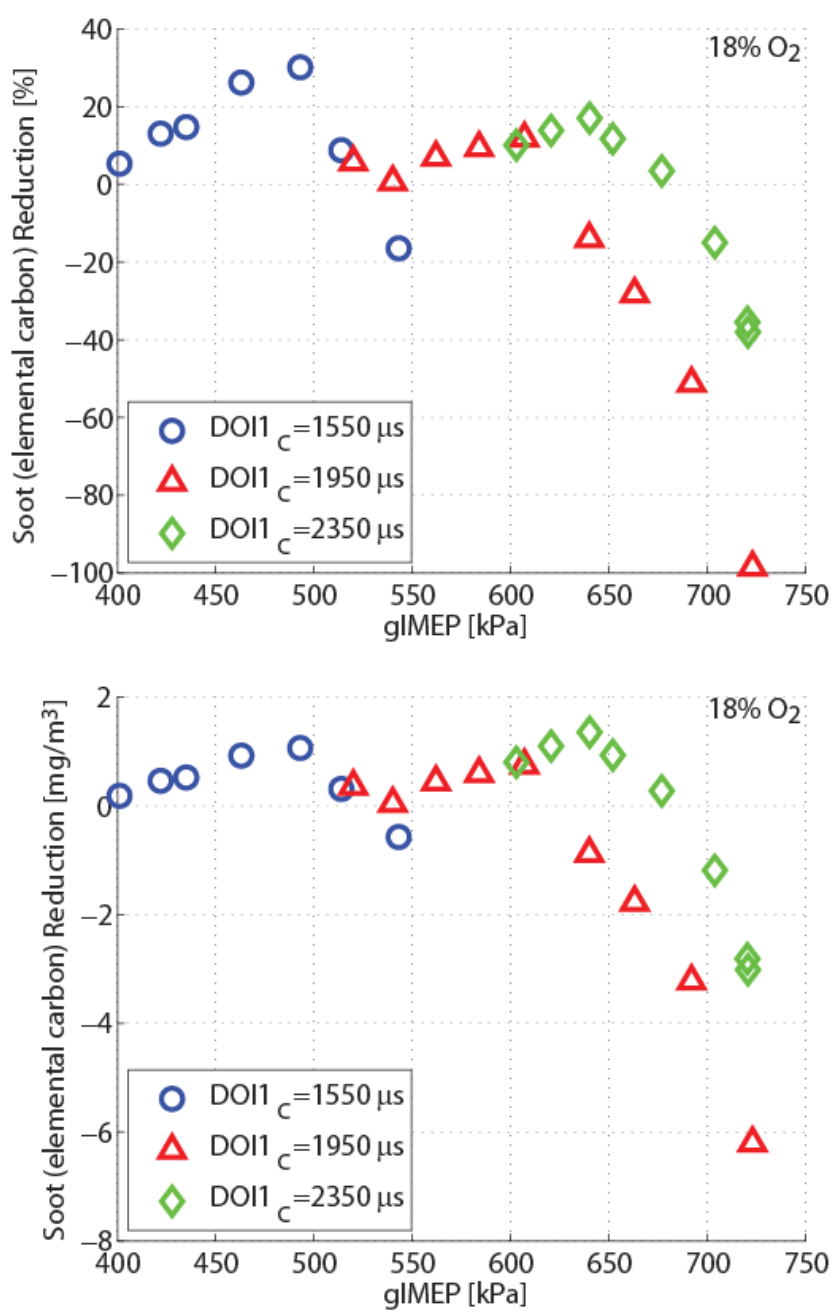

Figure 11. Percentage (top) and absolute (bottom) reduction in engine-out soot by main- plus post-injections compared to the main injection without a post for operation at three DOI1 ${ }_{C}$ with $18 \% O_{2}$ and SOI1 $=347$ CAD.

switch from reducing engine-out soot (at durations shorter than the cross-over) to increasing engine-out soot (at durations longer than the cross-over) at a constant load. The cross-over duration trends measured over a variety of tests at $21 \%$ and $18 \% \mathrm{O}_{2}$ indicate that the range of durations over which post injections can be effective at reducing soot decreases as the baseline load increase.

The engine-out soot data also provide some understanding of the in-cylinder mechanisms for the various dependencies of post-injection efficacy on load. In Figure 8, the non-monotonic shape of the engine-out soot curve for the main- plus postinjection schedule suggests a shift in the balance between two competing mechanisms affecting engine-out soot. One mechanism reduces engine-out soot, and is dominant for smaller post injections. This mechanism must involve an interaction between the post injection and the residual main-injection soot, since the main-injection duration remains unchanged as the post-injection duration is varied. This interaction becomes more effective as the post-injection duration increases, up to the point where the engine-out soot reaches a minimum $\left(\mathrm{DOI} 2_{\mathrm{C}}=500\right.$ microseconds for $\mathrm{DOI} 1_{\mathrm{C}}=1550$ and 1950 microseconds, and $\mathrm{DOI} 2_{\mathrm{C}}=300$ microseconds for $\mathrm{DOI} 1_{\mathrm{C}}=2350$ microseconds). After this point, soot reduction by postjet/main-soot interaction either becomes less effective, or it is offset by another soot-increasing mechanism. At some DOI $2_{C}-$ the cross-over point - the post injection becomes detrimental to engine-out soot levels, yielding higher engine-out soot than a single injection at the same load.

Additional understanding of the important in-cylinder mechanisms may be gained through analysis of the optical data. Figure 12 shows ensemble-average soot-NL images for the three load cases starting from the end of the post injection; shown here are the minimum soot conditions, where DOI $2_{C}=500$ microseconds for the DOI $1_{C}=1550$ and 1950 microsecond cases and DOI $2_{C}=300$ microseconds for the DOI1 $1_{C}=2350$ microseconds case. Similarly, instantaneous sootPLII images at these times are in Figure 13. Similar to the single-injection condition, the general signal evolution in the soot-PLII images mirrors the soot-NL images, so that largescale changes in the soot-NL signal can be attributed to changes in local soot concentration. Because of the test matrix choice constant start of injection, CSOI -the end of the post injection occurs at very similar times for all three load cases. Despite this similarity, the soot formation and evolution in the post jet is quite different in these three cases.

By the end of injection at $371 \mathrm{CAD}$, soot has formed in the post jet in all three cases. In each case, the soot first forms in the downstream portion of the jet, and progressively forms farther upstream. Eventually, soot forms closer to the injector for the higher load conditions; at $\mathrm{DOI} 1_{\mathrm{C}}=1550$ microseconds the soot forms as close as $15 \mathrm{~mm}$ from the injector and at DOI $1_{C}=2350$ microseconds the soot forms all the way up to the injector tip.

A major difference associated with $\mathrm{DOI} 2_{\mathrm{C}}$ in these cases is found in the post-jet penetration. For $\mathrm{DOI} 1_{\mathrm{C}}=1550$ and 1950 microseconds where the minimum engine-out soot occurs at $\mathrm{DOI} 2_{\mathrm{C}}=500$ microseconds, the post jet impinges on the bowl wall at $374 \mathrm{CAD}\left(3^{\circ} \mathrm{AEI} 2\right)$, spreading along the wall and becoming indistinguishable from the main-injection soot by $377 \mathrm{CAD}\left(6^{\circ} \mathrm{AEI} 2\right)$. In the $\mathrm{DOI} 1_{\mathrm{C}}=2350$ microsecond case, however, the minimum engine-out soot occurs at a shorter DOI2C $=300$ microseconds, for which the post jet does not impinge as much on the bowl wall. In this case, Figure 12 shows that soot in the post jet forms closer to the injector at $371 \mathrm{CAD}\left(0^{\circ} \mathrm{AEI} 2\right)$ and at $374 \mathrm{CAD}\left(3^{\circ} \mathrm{AEI} 2\right)$. However, by $377 \mathrm{CAD}\left(6^{\circ} \mathrm{AEI} 2\right)$, the post-injection soot and the maininjection soot have merged to the point where it is difficult to differentiate the two. At $380 \mathrm{CAD}\left(9^{\circ} \mathrm{AEI} 2\right)$, the region near the bowl wall along the jet centerline is relatively devoid of soot, unlike the other two load cases where the post jet has impinged on the bowl wall and spread. Additionally, a distinct 


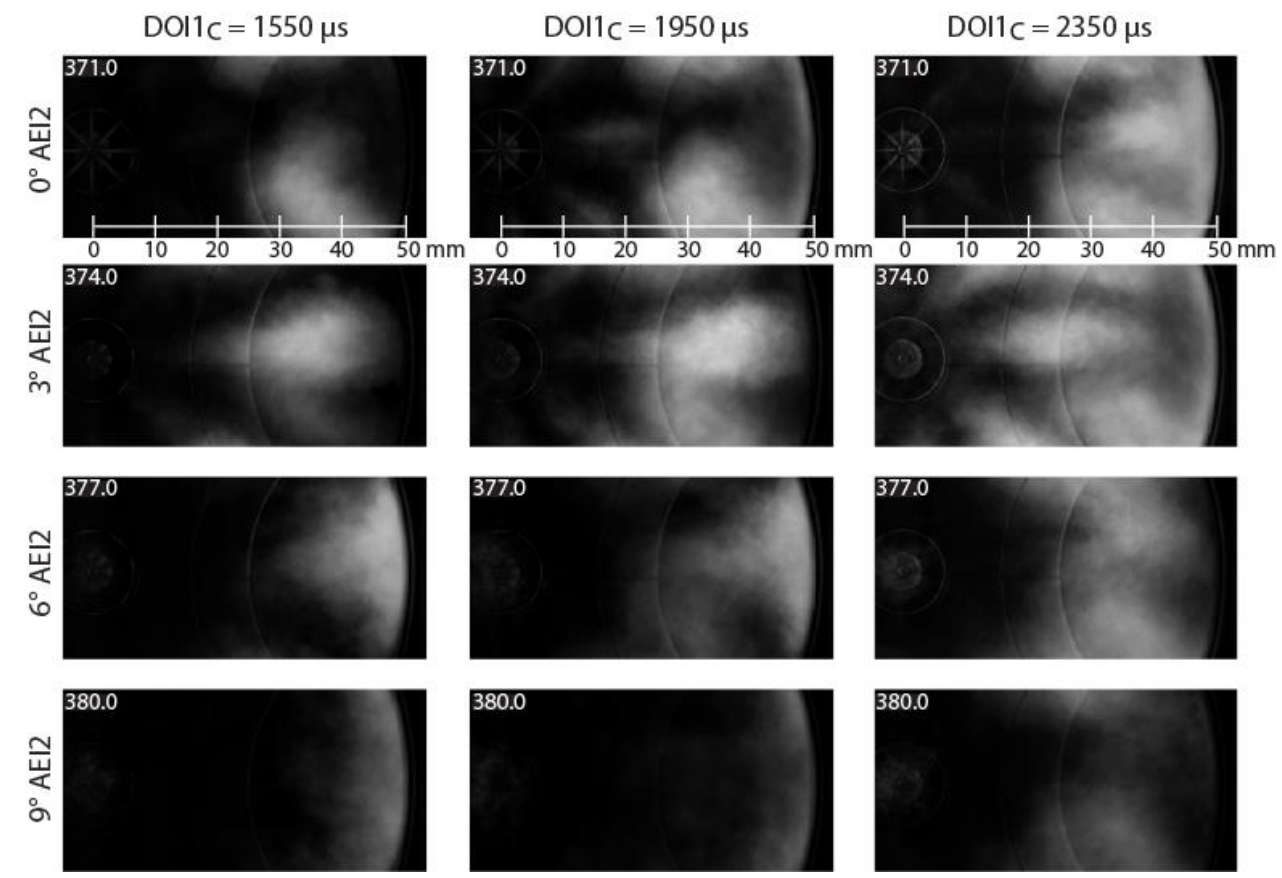

Figure 12. Ensemble-average soot-NL imaging of main- plus post-injection schedules of the minimum engine-out soot conditions at three loads (columns) and four timings after the end of injection (rows) with $18 \% \mathrm{O}_{2}$ and $\mathrm{SOI}_{\mathrm{C}}=347 \mathrm{CAD}$. Crank-angle timing is in the upper left corner of each image.
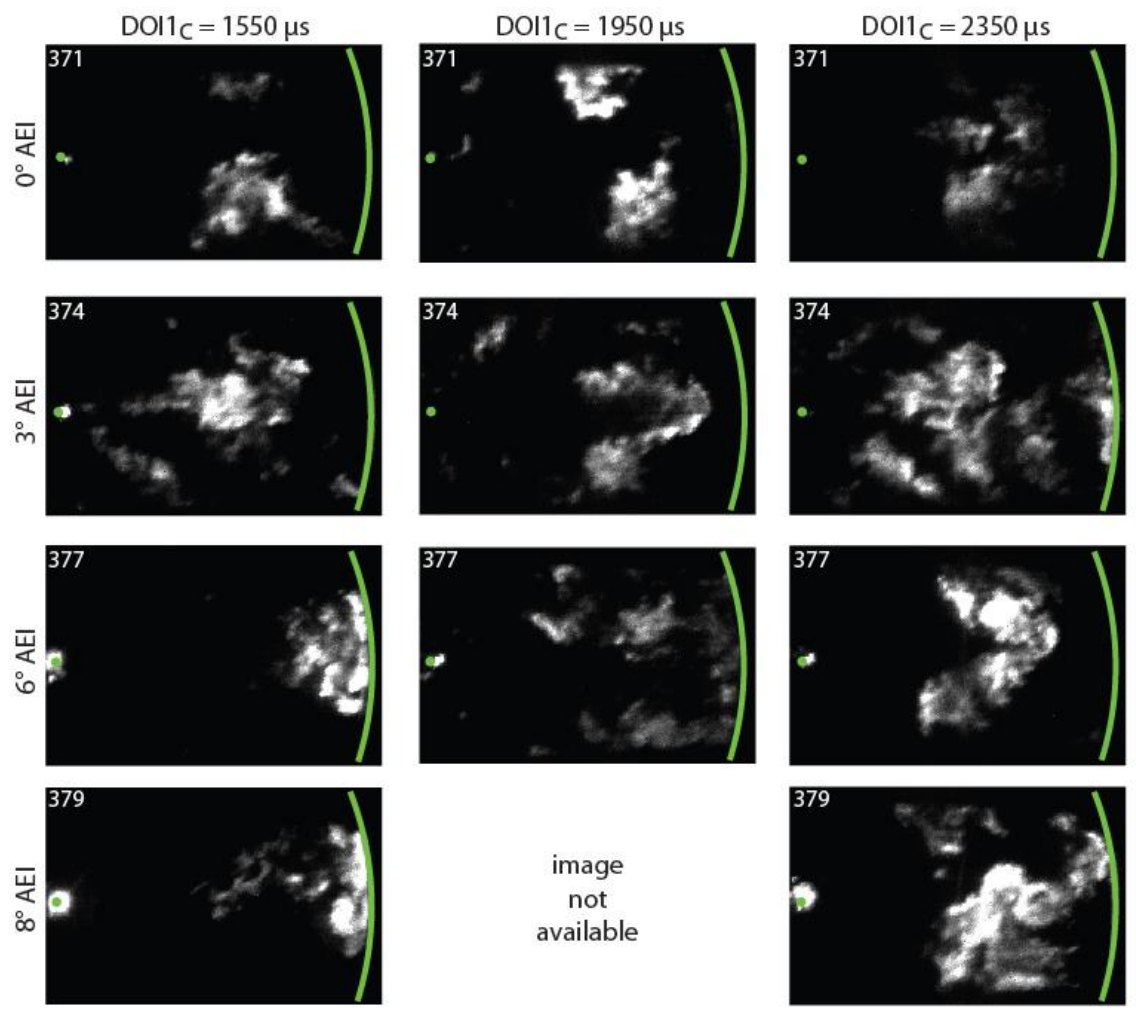

Figure 13. Instantaneous soot-PLII images of main- plus post-injection schedules at three loads (columns) and four timings after the end of injection (rows) with $18 \% \mathrm{O}_{2}$ and $\mathrm{SOI}_{\mathrm{C}}=347 \mathrm{CAD}$. The green dot at the left is the injector location and green line on the right is the bowl wall location. Crank-angle timing is in the upper left corner of each image. 
impingement of the post jet in the DOI1C $=2350$ microsecond case is not evident in the soot-PLII images in Figure 13; later in the cycle, the post-injection soot is indistinguishable from maininjection soot. These two clues indicate that the 300 microsecond post injection in the $\mathrm{DOI} 1_{\mathrm{C}}=2350$ microsecond case may not have impinged significantly on the bowl wall over the time interval of these images.

The differences in the post-jet structure and soot production likely stem from differences in the bulk thermal conditions for the three loads. Figure 14 shows cylinder pressure data for these three cases over the crank angles displayed in Figure 12.

The cylinder pressure data in Figure 14 indicate the difference in thermal conditions under which soot is formed in each of the post injections. The cylinder pressure at the highest load is approximately 5-7 bar higher than the lowest load across the crank angle span during which the post injection acts. This equates to approximately a 20-30 K temperature difference in the unmixed ambient gases (which are entrained into the fuel jets) between these two cases, calculated using isentropic relations. The thermal energy in the ambient fluid entrained into the fuel jet during the post injection affects mixture temperatures and thereby fuel vaporization, as well as flame temperatures and hence soot formation and oxidation. Soot formation, highly sensitive to ambient temperature [65] and dominant in these hot, fuel-rich regions, is thus accelerated at the high-load conditions. Furthermore, the lift-off length is shortened at higher ambient temperatures [44], also resulting in post injections that form more soot.

Additionally, changes to the post-jet structure reflect the variations in post-injection efficacy discussed in reference to Figure 8 above. While it would be very difficult to measure the effect of load - which encompasses increased main-injection duration, increased bulk temperature, and increased cylinder

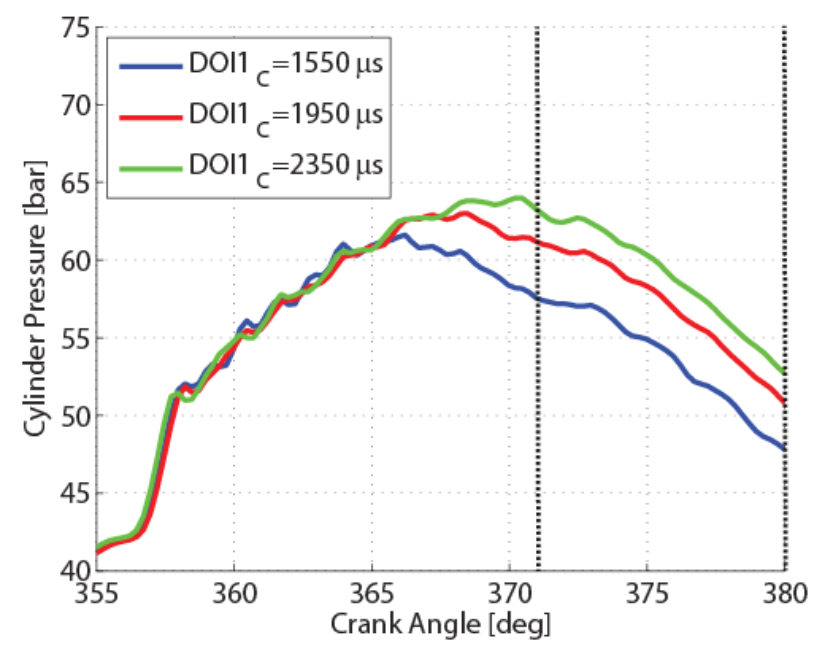

Figure 14. Measured cylinder pressure for three load conditions with main- plus post-injection schedules. Dotted vertical lines indicate start and end of visualization in Figure 12. pressure - on the post-jet/main-mixture interaction mechanism, it is clear from these images that the baseline load has an effect on the soot formation in the post jet itself. In the $\mathrm{DOI} 1_{C}=2350$ microsecond case in Figure 12, the post jet forms soot further upstream and most likely in greater quantities as a result of the higher bulk temperature at the higher load [43]. This means that the soot formation in the post jet is not only a function of the post-injection duration, but also of the thermal conditions in the cylinder. For a given post-injection duration, and with load adjusted by increasing main-injection duration while keeping all other engine operational parameters constant as in Table 2, the post jet will form more soot at a higher-load condition than at a lower-load condition.

This has two important repercussions on post-injection efficacy as a function of baseline load. First, the DOI $2_{C}$ at which soot is minimized occurs at shorter post-injection durations for higher loads because the post jet makes soot faster (as a function of $\mathrm{DOI} 2_{\mathrm{C}}$ ) than the interaction mechanism can enhance oxidation of the main-injection soot - this trade-off was discussed above with reference to Figure 8 . Second, the cross-over duration is shorter at higher loads where the post jet makes more soot. Post injections of shorter durations can make enough soot to overtake the enhanced soot oxidation that results from the post-jet/main-mixture interaction. Both these results (minimum soot at shorter $\mathrm{DOI} 2_{\mathrm{C}}$ and shorter cross-over durations) seem to indicate that the post-jet soot formation is more sensitive to load (in-cylinder thermal conditions) than the interaction mechanism. These two effects together help explain how the post injection is overall less effective at reducing engine-out soot at higher loads.

Only a few differences in the post-jet/main-mixture interaction are evident at the three load conditions with the optical data available with the ensemble-averaged soot-NL and single-shot soot-PLII techniques. Instantaneous high-speed imaging of the soot-NL provides additional information that helps to visualize and describe much of the interaction. Although the complete series of individual frames from the instantaneous high-speed image sets are not included here due to space limitations, the following description comes from videos that are available online [66-68].

As discussed with reference to Figure 6 and Figure 7 for the single-injection baseline, the main-injection soot distribution without a post injection is different for the three load cases; in particular, the spatial extent of the recirculation regions on either side of the jet centerline grows as the load increases. The spatial extent of these soot clouds has an effect on the degree of the direct interaction between the post jet and the main-injection soot. The high-speed soot-NL image sequences show that the post jet in the low- and mid-load cases does not interact much with the main-injection soot clouds; no pushing or entrainment of the main-injection soot by the post jet is visible in either of these cases (these were interaction mechanisms described in Ref. [46]).

The lack of interaction between the post injection and the main injection soot is quite evident when viewed dynamically in 
a movie of the high-speed soot-NL. Unfortunately, the same lack of interaction is much more difficult to discern from inspection of the same series images presented statically as in this presentation (The reader is encouraged to view the soot-NL movie for the same conditions as in Figure 15 available online [66]). Nevertheless, Figure 15 attempts to show an example of this lack of interaction through a time-series of instantaneous high-speed soot-NL images from the mid-load condition (DOI $1_{C}=1950$ microseconds). Colored outlines of the post injection (red) and main-injection soot (blue - lower recirculation zone only) in the instantaneous soot-NL images provide an approximate boundary of each of the structures, both of which were determined from the dynamic movie, where they are more easily discernible. These lines have been drawn for illustration purposes only and were not calculated using any quantitative edge-finding technique.

At 371.5 CAD, soot in the post jet forms downstream of the injector. As the jet continues to penetrate to the bowl wall (372-374 CAD), the post jet appears to pass over the lower recirculation zone, outlined in blue. During this time, the shape
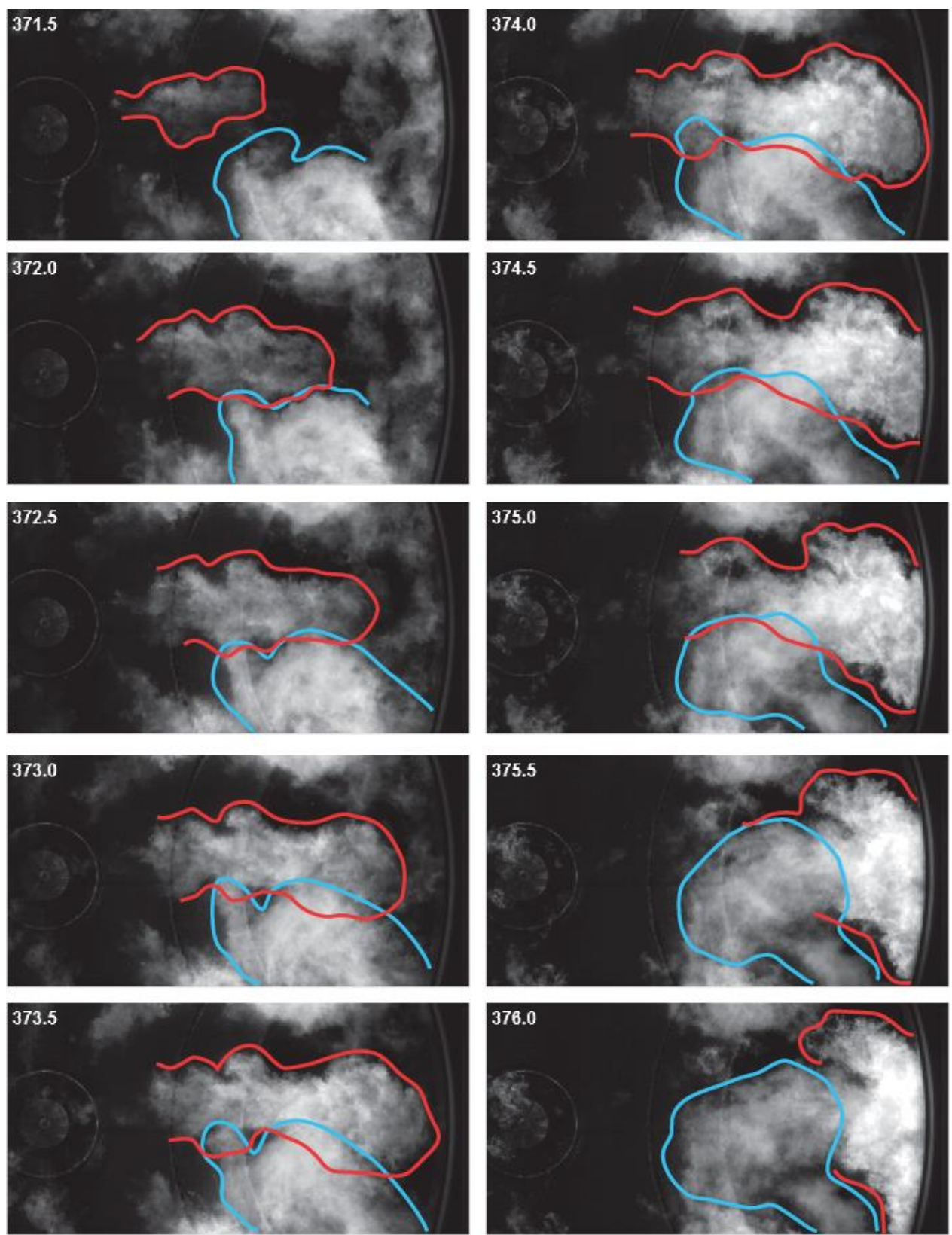

Figure 15. Instantaneous soot-NL images of main- plus post-injection schedule at the mid-soot condition with $18 \% \mathrm{O}_{2}$ SOI1 $=347$ CAD, DOI1C $=1950$ microseconds, SOI2C=366 CAD, and DOI2C=500 microseconds. Red outlines indicate approximate boundary of the post jet and blue outlines indicate approximate boundary of one main-injection recirculation zone. Crank-angle timing is in the upper left corner of each image. A video of this condition can be found at Ref. [66]. 
of that recirculation zone evolves slightly, but not as a result of interaction with the post jet; the structure's shape would change much more drastically if it interacted with the post jet (as is described later for higher loads). At 374.5 CAD, the post jet impinges on the bowl wall while the recirculation region continues to swirl counter-clockwise (up) around the bowl out of the plane of the post jet, shape relatively unchanged. Later, the post jet does appear to merge with the main-injection mixture as the jet impinges on the wall, spreading on either side of the jet centerline.

This lack of interaction may be due to both the lesser extent of the soot recirculation zones and the fact that much of the main-injection soot may be out of plane of the post jet. This can be seen in the soot-PLII images in Figure 13, which show very little main-injection soot present near the bowl in the plane of the jet at 374 CAD when the head of the post jet reaches the recirculation regions near the wall. This soot has likely moved deeper into the bowl as the piston descends, limiting the direct interaction between the post jet and the main-injection soot.

However, at the high load case, high-speed soot-NL imaging does show some indications of entrainment and merging of the main-injection soot into the tail of the post jet due to the greater spatial extent of the main-injection soot clouds, though this entrainment interaction is not easily discernible. This merging/entrainment is even more difficult to discern from a series of static images than is the lack of interaction presented in Figure 15. Hence, these static images are not presented here. Instead, an example of the entrainment process can be found in a high-speed movie available online [67]. For the sake of clarity, the video selected as an example of entrainment interaction between the post jet and the maininjection soot is for a longer post-injection duration (DOI $2_{C}=500$ microseconds) than that of the minimum-soot condition $\left(\mathrm{DOI} 2_{\mathrm{C}}=300\right.$ microseconds); the entrainment interaction is more discernible for the longer $\mathrm{DOI} 2_{\mathrm{C}}$, but the same interaction is also present at the shorter minimum-soot DOI $2_{\mathrm{C}}$.

In the video, the post injection begins at approximately 369.5 CAD, and soot first forms in the post jet at approximately 371 CAD. The post jet appears to displace the main-injection soot as it penetrates to the bowl wall, impinging on the wall at approximately $376 \mathrm{CAD}$. The tail of the post jet passes the main-injection recirculation zones at approximately $380 \mathrm{CAD}$, where it appears to entrain some of the main-injection soot into the tail of the post jet. During this process, soot in the recirculation zone is also oxidizing/cooling, which hinders discernment of fluid motion. Nevertheless, a change in the motion of this entrained structure toward the outward radial direction is evident. Later in the cycle, the entire residual soot cloud is more confined to the outer bowl than for the corresponding single-injection condition with the same DOI $1_{C}$ (see soot-NL video [68]), a result of entrainment into the post jet. The proximity of the recirculation-zone soot in the plane of the jet is also visible in Figure 13 at $374 \mathrm{CAD}$ in the DOI $1_{C}=2350$ microsecond case. The optical data suggests that the effect of load on the post-jet/main-mixture interaction mechanism is driven by the spatial extent of the main-injection soot in the path of the post jet. At higher load (longer DOI $1_{C}$ ), more soot is formed in the main-injection mixture and occupies a larger region in the bowl, intersecting with the post-jet path and leading to more direct interaction between post jet and main-injection mixture.

The interactions described here and in Ref. [46] may not be the only important interaction mechanisms between the post jet and the main-injection mixture. For example, the effect of endof-main-injection mixing on the main-injection soot cloud is clearly visible in Figure 6, where enhanced entrainment of fresh air into the soot-filled fuel jet at the end of injection likely helps to oxidize the soot in the jet. This enhanced oxidation reaches all the way to the bowl wall, carving out a sootless region along the jet centerline in between the two recirculation regions on either side of the jet in both the soot-NL and soot-PLII images. Enhanced end-of-injection mixing should also happen after the post injection, and may be an important soot-reduction mechanism in the post-jet/main-mixture interaction. Currently, however, it is difficult to visualize this effect or any others related to mixing with the current techniques. More optical data are required to further understand the interaction mechanism and the effect of baseline load on post-injection efficacy.

Several remaining questions need to be addressed to formulate a more complete description of how post injections reduce engine-out soot and how these mechanisms vary with engine operational parameters, including load. First, to what degree does the post injection interact directly with the maininjection products and how does this process change with load? In this study we've seen that varying load by changing maininjection duration can change the "initial conditions" for the post jet by altering the in-cylinder soot distribution. Additionally, some interaction mechanisms were identified, including entrainment of the main-injection soot into the post jet and pushing of the main-injection products by the post jet. The prominence of these mechanisms changed as the load (main-injection duration) varied. However, it is still unclear with the current diagnostic capability whether these types of interactions are essential for soot reduction by the post injection, and whether these interactions, or others, are reducing soot by enhancing oxidation of the main-injection soot or by reducing formation of soot overall.

Next, the diagnostics employed in this study have allowed us to visualize soot and fluid processes in the cylinder, but we are currently unable to measure thermal processes. Both soot formation and oxidation are highly dependent on temperature, and interactions between the post jet and main-injection soot could affect formation and oxidation in both the main- and postinjection soot. In-cylinder temperatures increase with load, as described in reference to Figure 12, where soot formation in the post injection varied with in-cylinder thermal conditions. Identifying the importance of thermal mechanisms is an important next step in understanding post-injection sootreduction mechanisms, particularly at a range of engine loads. 
Finally, this study addresses load variation in a particular manner - constant SOI (CSOI) - but as described in Appendix A, there are several ways to test post-injection efficacy at varying loads. It is unclear whether the understanding of postinjection mechanisms discussed in this study extends to these other injection schedules or if other post-injection processes become more important.

\section{CONCLUSIONS}

In this study we have explored role of load variation on post-injection efficacy for soot reduction at four different intake oxygen levels for a fixed start of both the main and the postinjection. Analysis of both engine-out soot measurements and two types of optical data, high-speed soot-NL and crank-angleresolved soot-PLII, have led to several conclusions about the dependence of post-injection efficacy on baseline load.

- For single-injection schedules at high-oxygen conditions, engine-out soot increases nearly linearly with load, as achieved by increasing injection duration. In the cylinder, the soot at higher loads resides in larger recirculation regions on either side of the jet centerline and along the bowl wall, particularly deeper in the bowl. Enhanced mixing after the end of injection helps to increase oxidation of soot along the jet centerline, but not in the recirculation regions.

- Post-injection efficacy compared to a single injection at the same load decreases on a percentage basis with increasing load at a variety of intake-oxygen levels, although the load trend of the absolute reduction in soot varies with intake-oxygen level. Post-injection efficacy compared to a single injection with the same duration as the main injection stays relatively constant as a function of load. Also, the cross-over point, or the post-injection duration at which the addition of a post injection is detrimental to engine-out soot levels at constant load, decreases with increasing baseline load. Finally, post-injection efficacy does not seem to be a function of injection dwell.

- Optical data indicate that the structure of the post jet changes as a function of load, which is a result of the different thermal conditions at the time of the post injection. At high load, the bulk temperature and pressure are higher, causing soot to form farther upstream in the post jet and in greater quantities.

- The enhanced soot formation in the post jet at higher loads ultimately decreases its net efficacy. Among other possible factors, post-injection efficacy is a balance between the enhanced oxidation of soot by the post-jet/main-mixture interaction mechanism and the soot formed in the post jet itself. While this interaction mechanism may be weakly dependent on load, the soot formation in the post jet is strongly dependent on load and the resulting in-cylinder thermal conditions. This functional imbalance in these two processes as it relates to load appears to cause post injections to be less effective at reducing soot at higher loads.

\section{ACKNOWLEDGMENTS}

The optical engine experiments were performed at the Combustion Research Facility, Sandia National Laboratories, Livermore, CA. Support for this research was provided by the U.S. Department of Energy, Office of Vehicle Technologies. Sandia is a multi-program laboratory operated by Sandia Corporation, a Lockheed Martin Company for the United States Department of Energy's National Nuclear Security Administration under contract DE-AC04-94AL85000. The authors gratefully acknowledge the contributions of Keith Penney and Dave Cicone for their assistance in maintaining the lasers and research engine used in this study.

\section{REFERENCES}

1. United States Environmental Protection Agency, "Fact sheet: diesel exhaust in the United States" EPA420-F03-022 (2003)

2. "United States Code of Federal Regulations, Title 40, part 86" (2013)

3. European Parliament, "Regulation (EC) No 595/2009 of 18 June 2009" (2009)

4. DieselNet. Available from: http://www.dieselnet.com/ (2009)

5. Musculus M P B, Miles P C, Pickett L M, "Conceptual models for partially premixed low-temperature diesel combustion" Prog. Energy Combust. Sci. 39(2-3):246283 (2013)

6. de Ojeda W, Zoldak P, Espinosa R, Kumar R, "Development of a fuel injection strategy for diesel LTC" SAE Technical Paper 2008-01-0057 (2008)

7. Kanda $T$, Hakozaki $T$, Uchimoto $T$, Hatano J, Kitayama N, Sono H, "PCCI operation with fuel injection timing set close to TDC" SAE Technical Paper 2006-01-0920 (2006)

8. Kim D, Ekoto I, Colban W F, Miles P C, "In-cylinder $\mathrm{CO}$ and UHC imaging in a light-duty diesel engine during PPCI low-temperature combustion" SAE Technical Paper 2008-01-1602, SAE Int. J. Fuels Lubr. 1(1):933-956 (2008)

9. Han M, Assanis D N, Bohac S V, "Sources of hydrocarbon emissions from low-temperature premixed compression ignition combustion from a common rail direct injection diesel engine" Combust. Sci. Technol. 181(3):496-517 (2009)

10. Lachaux $\mathrm{T}$ and Musculus $\mathrm{M} \mathrm{P}$ B, "In-cylinder unburned hydrocarbon visualization during lowtemperature compression-ignition engine combustion using formaldehyde PLIF" Proc. Combust. Inst. 31(2):2921-2929 (2007)

11. Musculus M P B, Lachaux T, Pickett L M, Idicheria C A, "End-of-injection over-mixing and unburned 
hydrocarbon emissions in low-temperature-combustion diesel engines" SAE Technical Paper 2007-01-0907, SAE Trans. 116(3):515-541 (2007)

12. O'Connor $\mathrm{J}$ and Musculus M P B, "Post injections for soot reduction in diesel engines: A review of current understanding" SAE Technical Paper 2013-01-0917, SAE Int. J. Eng. 6(1) (2013)

13. Bobba M, Musculus M P B, Neel W, "Effect of post injections on in-cylinder and exhaust soot for lowtemperature combustion in a heavy-duty diesel engine" SAE Technical Paper 2010-01-0612, SAE Int. J. Engines 3(1):496-516 (2010)

14. Desantes J M, Arrègle J, López J J, García A, "A comprehensive study of diesel combustion and emissions with post-injection" SAE Technical Paper 2007-01-0915, SAE Trans. 116(3):542-550 (2007)

15. Hotta Y, Inayoshi M, Nakakita K, Fujiwara K, Sakata I, "Achieving lower exhaust emissions and better performance in an HSDI diesel engine with multiple injection" SAE Technical Paper 2005-01-0928, SAE Trans. 114(3):883-898 (2005)

16. Pierpont D A, Montgomery D T, Reitz R D, "Reducing particulate and NOx using multiple injections and EGR in a D.I. diesel" SAE Technical Paper 950217, SAE Trans. 104(3):1041-1050 (1995)

17. Barro C, Tschanz F, Obrecht P, Boulouchos K, "Influence of post-injection parameters on soot formation and oxidation in a common-rail-diesel engine using multi-color-pyrometry" ICEF201292075, ASME Internal Combustion Engine Division Fall Technical Conference, Vancouver BC (2012)

18. Payri F, Benajes J, Pastor J V, Molina S, "Influence of the post-injection pattern on performance, soot and NOx emissions in a HD diesel engine" SAE Technical Paper 2002-01-0502 (2002)

19. Benajes J, Molina S, García J M, "Influence of preand post-injection on the performance and pollutant emissions in a HD diesel engine" SAE Technical Paper 2001-01-0526, SAE Trans. 110(3):361-371 (2001)

20. Chen S K, "Simultaneous reduction of NOx and particulate emissions by using multiple injections in a small diesel engine" SAE Technical Paper 2000-013084, SAE Trans. 109(3):2127-2136 (2000)

21. Shayler P J, Brooks T D, Pugh G J, Gambrill R, "The influence of pilot and split-main injection parameters on diesel emissions and fuel consumption" SAE Technical Paper 2005-01-0375 (2005)

22. Greeves G, Tullis S, Barker B, "Advanced twoactuator EUI and emission reduction for heavy-duty diesel engines" SAE Technical Paper 2003-01-0698, SAE Trans. 112(3):914-931 (2003)

23. Mendez S and Thirouard B, "Using multiple injection strategies in diesel combustion: potential to improve emissions, noise and fuel economy trade-off in low CR engines" SAE Technical Paper 2008-01-1329, SAE Int. J. Fuels Lubr. 1(1):662-674 (2009)

24. Dronniou N, Lejeune M, Balloul I, Higelin P, "Combination of high EGR rates and multiple injection strategies to reduce pollutant emissions" SAE Technical Paper 2005-01-3726 (2005)

25. Tanin K V, Wickman D D, Montgomery D T, Das S, Reitz R D, "The influence of boost pressure on emissions and fuel consumption of a heavy-duty single-cylinder D.I. diesel engine" SAE Technical Paper 1999-01-0840, SAE Trans. 108(3):1148-1219 (1999)

26. Vanegas A, Won H, Felsch C, Gauding M, Peters N, "Experimental investigation of the effect of multiple injections on pollutant formation in a common-rail DI diesel engine" SAE Technical Paper 2008-01-1191 (2008)

27. Montgomery D T and Reitz R D, "Effects of multiple injections and flexible control of boost and EGR on emissions and fuel consumption of a heavy-duty diesel engine" SAE Technical Paper 2001-01-0195, SAE Trans. 110(3):33-54 (2001)

28. Yun H and Reitz R D, "An experimental investigation on the effect of post-injection strategies on combustion and emissions in the low-temperature diesel combustion regime" J. Eng. Gas Turb. Power 129:279286 (2007)

29. Ehleskog R and Ochoterena R L, "Soot evolution in multiple injection diesel flames" SAE Technical Paper 2008-01-2470 (2008)

30. Yun H, Sun Y, Reitz R D, "An experimental and numerical investigation on the effect of post injection strategies on combustion and emissions in the lowtemperature diesel combustion regime" ICES20051043, ASME Internal Combustion Engine Division 2005 Spring Technical Conference, Chicago IL (2005)

31. Bakenhus M and Reitz R D, "Two-color combustion visualization of single and split injections in a singlecylinder, heavy-duty D. I. diesel engine using an endoscope-based imaging system" SAE Technical Paper 1999-01-1112, SAE Trans. 108(3):1567-1584 (1999)

32. Badami M, Mallamo F, Millo F, Rossi E, "Experimental investigation on the effect of multiple injection strategies on emissions, noise and brake specific fuel consumption of an automotive direct injection common-rail diesel engine" Int. J. Engine Res. 4(4):299-314 (2003)

33. Helmantel A, Somhorst J, Denbratt I, "Visualization of the effects of post injection and swirl on the combustion process of a passenger car common rail DI diesel engine" ICES2003-622, Spring Technical Conference of ASME ICE Division, Salzberg Austria (2003) 
34. Mancaruso E, Merola S, Vaglieco B, "Study of the multi-injection combustion process in a transparent direct injection common rail diesel engine by means of optical techniques" Int. J. Engine Res. 9(6):483-498 (2008)

35. Han Z, Uludogan A, Hampson G J, Reitz R D, "Mechanism of soot and NOx emission reduction using multiple-injection in a diesel engine" SAE Technical Paper 960633, SAE Trans. 105(3):837-852 (1996)

36. Molina S, Desantes J M, Garcia A, Pastor J M, "A numerical investigation on combustion characteristics with the use of post injection in DI diesel engines" SAE Technical Paper 2010-01-1260 (2010)

37. Beatrice C, Belardini P, Bertoli C, Lisbona M, Sebastiano G M R, "Diesel combustion control in common rail engines by new injection strategies" Int. J. Engine Res. 3(1):23-36 (2002)

38. Arrègle J, Pastor J V, López J J, García A, "Insights on postinjection-associated soot emissions in direct injection diesel engines" Combust. Flame 154(3):448461 (2008)

39. Dec J E, "A conceptual model of DI diesel combustion based on laser-sheet imaging" SAE Technical Paper 970873, SAE Trans. 106(3):1319-1348 (1997)

40. Tow T C, Pierpont D A, Reitz R D, "Reducing particulate and NOx emissions by using multiple injections in a heavy duty D.I. diesel engine" SAE Technical Paper 940897, SAE Trans. 103(3):14031417 (1994)

41. Official Journal of the European Communities, "EEC Directive 90/C81/01" (1990)

42. Official Journal of the European Communities, "Directive 1999/96/EC" (1999)

43. Pickett L M and Siebers D L, "Soot in diesel fuel jets: effects of ambient temperature, ambient density, and injection pressure" Combust. Flame 138(1):114-135 (2004)

44. Siebers D L and Higgins B, "Flame lift-off on directinjection diesel sprays under quiescent conditions" SAE Technical Paper 2001-01-0530, SAE Trans. 110(3):400-421 (2001)

45. Pickett L and Siebers D, "Soot formation in diesel fuel jets near the lift-off length" Int. J. Engine Res. 7(2):103-130 (2006)

46. O'Connor $\mathrm{J}$ and Musculus M, "Effects of EGR and load on soot in a heavy-duty optical diesel engine with close-coupled post-injections for high efficiency combustion phasing" accepted in Int. J. Eng. Res. (2013)

47. Murphy M J, Taylor J D, McCormick R L, "Compendium of experimental cetane number data" National Renewable Energy Laboratory NREL/SR540-36805 (2004)
48. Idicheria C and Pickett L, "Ignition, soot formation, and end-of-combustion transients in diesel combustion under high-EGR conditions" Int. J. Engine Res. 12(4):376-392 (2011)

49. Musculus M P, Dec J E, Tree D R, "Effects of fuel parameters and diffusion flame lift-off on soot formation in a heavy-duty DI diesel engine" SAE Technical Paper 2002-01-0889, SAE Trans. 111(3):1467-1489 (2002)

50. Heywood J B, Internal combustion engine fundamentals, McGraw-Hill, New York, NY (1988)

51. Kolodziej C, Wirojsakunchai E, Foster D E, Schmidt N, Kamimoto T, Kawai T, Akard M, Yoshimura T, "Comprehensive characterization of particulate emissions from advanced diesel combustion" SAE Technical Paper 2007-01-1945 (2007)

52. Lilik G K and Boehman A L, "Advanced diesel combustion of a high cetane number fuel with low hydrocarbon and carbon monoxide emissions" Energy \& Fuels 25(4):1444-1456 (2011)

53. Smoke value measurement with the filter-papermethod: Application notes, AVL List GmbH: Graz, Austria (2005)

54. Cheng A, Upatnieks A, Mueller C J, "Investigation of fuel effects on dilute, mixing-controlled combustion in an optical direct-injection diesel engine" Energy \& Fuels 21(4):1989-2002 (2007)

55. Chartier C, Andersson Ö, Johansson B, Musculus M, Bobba M, "Effects of post-injection strategies on nearinjector over-lean mixtures and unburned hydrocarbon emission in a heavy-duty optical diesel engine" SAE Technical Paper 2011-01-1383, SAE Int. J. Engines 4(1):1978-1992 (2011)

56. Schulz C, Kock B F, Hofmann M, Michelsen H, Will S, Bougie B, Suntz R, Smallwood G, "Laser-induced incandescence: recent trends and current questions" Appl. Phys. B - Lasers O 83(3):333-354 (2006)

57. Colban W F, Kim D, Miles P C, Oh S, Opat R, Krieger R, Foster D, Durrett R P, Gonzalez D M A, "A detailed comparison of emissions and combustion performance between optical and metal single-cylinder diesel engines at low temperature combustion conditions" SAE Technical Paper 2008-01-1066, SAE Int. J. Fuels Lubr. 1(1):505-519 (2009)

58. Cooper B, Penny I, Beasley M, Greaney A, Crump J, "Advanced diesel technology to achieve tier 2 bin 5 emissions compliance in US light-duty diesel applications" SAE Technical Paper 2006-01-1145 (2006)

59. Nehmer D A and Reitz R D, "Measurement of the effect of injection rate and split injections on diesel engine soot and NOx emissions" SAE Technical Paper 940668, SAE Trans. 105(3):1030-1041 (1994)

60. Bower G R and Foster D E, "The effect of split injection on fuel distribution in an engine-fed 
combustion chamber" SAE Technical Paper 930864, SAE Trans. 102(3):1187-1202 (1993)

61. Musculus M P B, "Effects of the in-cylinder environment on diffusion flame lift-off in a DI diesel engine" SAE Technical Paper 2003-01-0074, SAE Trans. 112(3):314-337 (2003)

62. Musculus M P B and Kattke K, "Entrainment waves in diesel jets" SAE Technical Paper 2009-01-1355, SAE Int. J. Engines 2(1):1170-1193 (2009)

63. Hu B, Musculus M P B, Oefelein J C, "The influence of large-scale structures on entrainment in a decelerating transient turbulent jet revealed by large eddy simulation" Phys. Fluids 24:045106 (2012)

64. Bobba M K, Genzale C L, Musculus M P B, "Effect of ignition delay on in-cylinder soot characteristics of a heavy duty diesel engine operating at low temperature conditions" SAE Technical Paper 2009-01-0946, SAE Int. J. Engines 2(1):911-924 (2009)

65. Glassman I, "Soot formation in combustion processes" Proc. Combust. Inst. 22(1):317-378 (1989)

66. O'Connor J and Musculus M P B, Soot-NL video, $18 \%$ $\mathrm{O}_{2}, \mathrm{SOII}_{C}=347 \mathrm{CAD}, \mathrm{DOII}_{C}=1950$ microseconds, $\mathrm{SOI}_{C}=366 \mathrm{CAD}, \quad$ DOI ${ }_{C}=500$ microseconds. Available from: $\quad$ www.sandia.gov/ecn/publinks/cdl/1203291_annotated.php (2013)

67. O'Connor J and Musculus M P B, Soot-NL video, $18 \%$ $\mathrm{O}_{2}, \mathrm{SOII}_{C}=347 \mathrm{CAD}, \mathrm{DOII}_{C}=2350$ microseconds, $\mathrm{SOI}_{C}=368 \mathrm{CAD}, \quad \mathrm{DOI}_{C}=500$ microseconds. Available from: $\quad$ www.sandia.gov/ecn/publinks/cdl/120515r_annotated.php (2013)

68. O'Connor J and Musculus M P B, Soot-NL video, $18 \%$ $\mathrm{O}_{2}, \mathrm{SOII}_{\mathrm{C}}=347 \mathrm{CAD}, \mathrm{DOII}_{\mathrm{C}}=2350$ microseconds. Available from: www.sandia.gov/ecn/publinks/cdl/120515o.php (2013)

69. Miles P C, "Turbulent flow structure in directinjection, swirl-supported diesel engines flow and combustion in reciprocating engines" in Flow and combustion in reciprocating engines, ed. C. Arcoumanis and T. Kamimoto, Springer Berlin, Heidelberg Germany (2009) 


\section{APPENDIX A - TEST MATRIX OVERVIEW}

Four variables were identified as "knobs" that could be varied to test the effect of load on post-injection efficacy: start of the main injection (SOI1), end of the main injection (EOI1), start of the post injection (SOI2), and injection dwell (time between EOI and SOI2). Table A1 shows the three possible test methodologies that hold certain variables constant while allowing others to vary, as well as benefits and drawbacks of each strategy. Figure A1 provides a graphic representation of each of the strategies outlined in Table A1.

The constant start of injection (CSOI) strategy keeps the start of the main injection and start of the post injection constant while varying the dwell between the end of the main injection and the start of the post injection. Keeping SOI1 constant allows for a similar main-injection combustion phasing across tests, which is important for maintaining performance and emissions baselines. Also, constant SOI2 allows the post injection to interact with the same combustion chamber geometry (piston location) for each test. Maintaining cylinder geometry is important from a fluid-dynamic interaction perspective; the engine flow field is largely determined by the shape of the combustion chamber and movement of the piston [69]. Placing a post-injection at different times during the cycle could alter the fluid-mechanical mechanisms by which a post injection may reduce soot. However, changing the dwell between the end of the main injection and the beginning of the post injection places the post injection during a different time in the spatio-temporal development of the main-injection mixture. By changing the "initial conditions" of the post injection, one may also alter the way that the post jet interacts with the maininjection mixture.

The constant-dwell/variable-phase (CDVP) strategy tries to alleviate the issues of varying the injection dwell by holding the "back end" of the injection schedule (EOI1, dwell, SOI2) constant while changing SOI1 to increase the duration of the main injection and hence the load. Maintaining a constant dwell and SOI2 are beneficial for understanding fluid-mechanic mechanisms as the spatio-temporal evolution of the maininjection mixture and chamber geometry is the same across different loads. However, changing the start of the main

Table A1. Test matrix trade-offs. " $X$ " indicates that the quantity for that column is held constant.

\begin{tabular}{|l|c|c|c|c|l|l|}
\hline & SOI1 & EOI1 & SOI2 & Dwell & Pros & Cons \\
\hline $\begin{array}{l}\text { Constant } \\
\text { SOI (CSOI) }\end{array}$ & $\mathrm{X}$ & & $\mathrm{X}$ & & $\begin{array}{l}\text { Similar } \\
\text { combustion } \\
\text { phasing }\end{array}$ & $\begin{array}{l}\text { Changes in } \\
\text { injection } \\
\text { dwell }\end{array}$ \\
\hline $\begin{array}{l}\text { Constant } \\
\text { dwell/ } \\
\text { variable } \\
\text { phasing } \\
\text { (CDVP) }\end{array}$ & & $\mathrm{X}$ & $\mathrm{X}$ & $\mathrm{X}$ & $\begin{array}{l}\text { Constant } \\
\text { injection } \\
\text { dwell }\end{array}$ & $\begin{array}{l}\text { Changes to } \\
\text { combustion } \\
\text { phasing }\end{array}$ \\
\hline $\begin{array}{l}\text { Constant } \\
\text { dwell/ } \\
\text { constant } \\
\text { phasing } \\
\text { (CDCP) }\end{array}$ & $\mathrm{X}$ & & $\mathrm{X}$ & $\begin{array}{l}\text { Constant } \\
\text { injection } \\
\text { dwell }\end{array}$ & $\begin{array}{l}\text { Changing } \\
\text { cylinder } \\
\text { geometry } \\
\text { for post }\end{array}$ \\
\hline
\end{tabular}

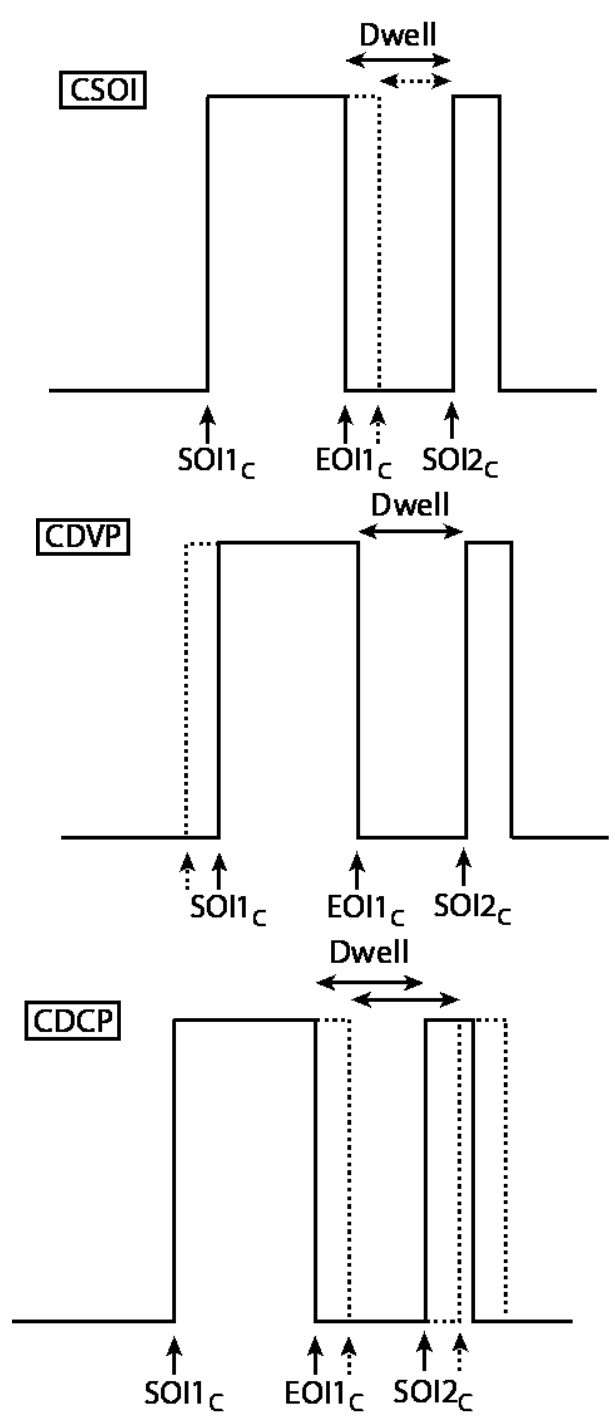

Figure A1. Graphical representations of test matrix options Constant start of injection (CSOI), constant dwell/variable phasing (CDVP), and constant dwell/constant phasing (CDCP).

injection can significantly change the combustion phasing and details of the combustion event, changing both the thermodynamic conditions and the flow field at the end of the main injection. This change in combustion phasing may be severe enough to render the aforementioned benefits of the CDVP strategy moot, and hence this strategy is not employed in this study.

The constant-dwell/constant-phase (CDCP) strategy holds the combustion phasing constant by maintaining SOI1 and keeps dwell constant to maintain some of the fluid-mechanic similarity between each load condition. However, this strategy does not account for the differences in chamber geometry at SOI2 for each load condition. Previous studies [13, 15, 16] have indicated that the targeting of the post injection with respect to the chamber geometry may play a significant role in the efficacy of the post injection and the mechanism by which it 
reduces soot. For example, work by Bobba et al. [13] points to interactions of the post jet with main-injection mixture in the squish region as a mechanism by which the post injection and main-injection products may interact to reduce soot. However, this mechanism is only achievable at very late post-injection timings, where the piston has dropped far enough for the shallow-angle spray to access the squish region.

Previous work by the authors [46] has shown that soot can be reduced from a single-injection baseline by close-coupled post injections that interact with the main-injection mixture in the bowl, without the squish region playing a significant role in the mechanism. In general, by moving SOI2 later in the cycle, one runs the risk of significantly changing the post jet/maininjection mixture interaction. Additionally, moving SOI2 later can also change the soot formation/oxidation process due to the changes to the ambient conditions - cooler temperature and lower pressure - that occur later in the cycle. Cooler temperatures could suppress soot oxidation; even if the post jet interacts with the main-injection soot, the thermal conditions may be unsuitable for enhanced oxidation. Further, time for oxidation is shortened as the post injection is pushed later, moving the main/post interaction closer towards EVO and allowing less time for soot oxidation chemistry to take place.

In this study we have adopted the CSOI approach across the three load conditions. This methodology is chosen because of the constant chamber geometry and similar ambient conditions at and after $\mathrm{SOI}_{2}$ compared to the other options, even though the dwell time between injection is not constant. Although changes to dwell time can change the "initial conditions" of the main-injection mixture into which the postjet penetrates, engine-out soot measurements indicate that over a range of injection dwells, from $2 \mathrm{CAD}$ to $10.5 \mathrm{CAD}$, the trend in post-injection efficacy does not change significantly, indicating that variation in dwell may not be a confounding issue for interpreting post-injection efficacy at different loads. Figure A2 shows the results of the dwell-duration sweep at three different conditions to illustrate the insensitivity of postinjection trends to dwell time at three conditions.

As is indicated in Figure A2, the trend in post-injection efficacy is relatively insensitive to post-injection dwell at several conditions. At $21 \%$ and $18 \% \mathrm{O}_{2}$, the trends in engineout soot and post-injection efficacy are very similar, indicating that dwell-insensitivity holds at several main-injection durations. Additionally, post-injection efficacy does not seem sensitive to dwell time at lower intake-oxygen levels, as seen in Figure A2 (bottom) at $12.6 \% \mathrm{O}_{2}$, despite the differences in postinjection trends between the high- and low-intake oxygen levels. This insensitivity to dwell combined with an interest in studying fluid-mechanic interactions between the post jet and the main-injection mixture lead to the choice of the CSOI injection schedule.
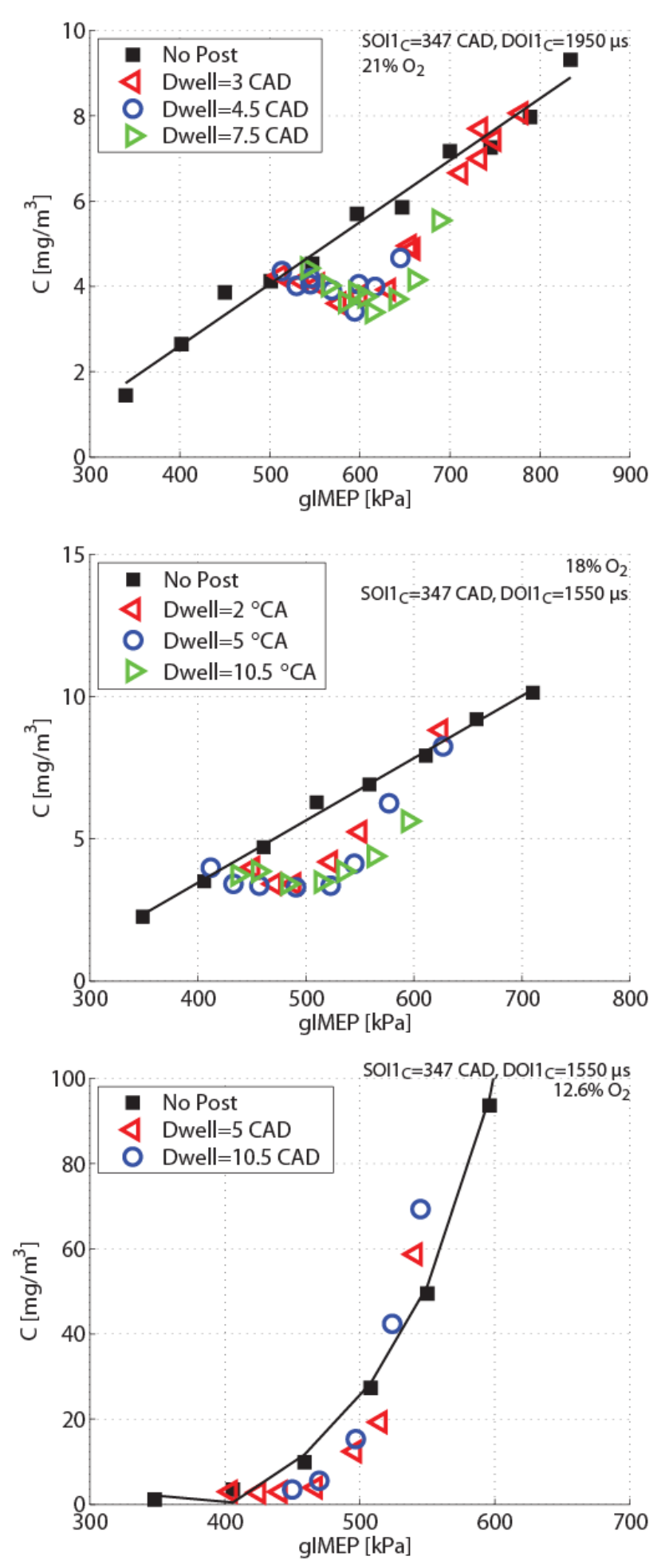

Figure A2. Sensitivity of post-injection efficacy to injection dwell at $21 \% \mathrm{O}_{2}$, DOI1 $_{\mathrm{C}}=1950$ microseconds (top), $18 \% \mathrm{O}_{2}$, DOI $_{\mathrm{C}}=1550$ microseconds (middle), and $12.6 \% \mathrm{O}_{2}$, DOI1 $_{C}=1550$ microseconds (bottom). 